\title{
Novel synthesis, characterization and TDD-DFT computations for ZrO2-bromothymol blue nanocomposite thin film [ZrO2+BTB]C and its application
}

Ahmed F. Al-Hossainy ( $\nabla$ ahmed73chem@scinv.au.edu.eg )

Northern border University https://orcid.org/0000-0001-5531-6940

Mohamed Sh. Zoromba

King Abdulaziz University

\section{Research Article}

Keywords: Nanocomposite [ZrO2+BTB]C, XRD, DFT, thin films, optical properties

Posted Date: March 19th, 2021

DOI: https://doi.org/10.21203/rs.3.rs-321215/v1

License: (c) (1) This work is licensed under a Creative Commons Attribution 4.0 International License. Read Full License 


\title{
Novel synthesis, characterization and TDD-DFT computations for $\mathrm{ZrO}_{2}$ - bromothymol blue nanocomposite thin film $\left[\mathrm{ZrO}_{2}+\mathrm{BTB}\right]^{\mathrm{C}}$ and its application
}

\author{
Ahmed F. Al-Hossainy*1, and Mohamed Sh. Zoromba ${ }^{2,3}$ \\ ${ }^{1}$ Chemistry Department, Faculty of Science, Northern border University, 13211 Arar, Saudi Arabia \\ ${ }^{2}$ Chemical and Materials Engineering Department, King Abdulaziz University, Rabigh 21911, Saudi Arabia \\ ${ }^{3}$ Chemistry Department, Faculty of Science, 23 December Street, 42521, Port-Said University, Port-Said, Egypt
}

\begin{abstract}
A novel $\left[\mathrm{ZrO}_{2}+\mathrm{BTB}\right]^{\mathrm{C}}$ nanocomposite was synthesized and prepared as a thin film using the Sol-Gel spin coating method. Different characterization techniques for $\left[\mathrm{ZrO}_{2}+\mathrm{BTB}\right]^{\mathrm{C}}$ like FTIR, UV-Vis, and optical properties have been used. The resulted XRD and SEM data have been employed to study interface composites. The optimization was performed using DFT by $\mathrm{DMol}^{3}$ and CASTEP program. The chemical structure was confirmed by spectroscopic and structural properties for $\left[\mathrm{ZrO}_{2}-\mathrm{BTB}\right]^{\mathrm{C}}$, XRD results showed the same crystal structure. Combined between experimental and TDD-DFT data, the average crystallite size and composite interface are $12.36 \mathrm{~nm}$ and orthorhombic symmetry $(a=7.38(5) ; b=$ 18.178(6); $\mathrm{c}=26.10(3) \AA$ and $\mathrm{a}=\mathrm{b}=\mathrm{g}=90^{\circ}$ ) with space group $\left(\mathrm{P} 6_{1}\right)$ for $\left[\mathrm{ZrO}_{2}+\mathrm{BTB}\right]^{\mathrm{C}}$, respectively. Furthermore. While the computed by DFT are $2.897 \mathrm{eV}$ and $2.492 \mathrm{eV}$ for as-isolated crystals of $[\mathrm{BTB}]^{\mathrm{TF}}$ and $\left[\mathrm{ZrO}_{2}+\mathrm{BTB}\right]^{\mathrm{C}}$, respectively. Both $[\mathrm{BTB}]^{\mathrm{TF}}$ and $\left[\mathrm{ZrO}_{2}+\mathrm{BTB}\right]^{\mathrm{C}}$ thin films have direct allowed transitions. In addition, the optoelectrical parameters have been calculated for $[\mathrm{BTB}]^{\mathrm{TF}}$ and $\left[\mathrm{ZrO}_{2}+\mathrm{BTB}\right]^{\mathrm{C}}$ films such as refractive index, extinction coefficient, dielectric constant, and optical conductivity. The simulated values obtained by CATSTEP for the optical parameters of $\left[\mathrm{ZrO}_{2}+\mathrm{BTB}\right]^{\mathrm{C}}$ are in good agreement with the experimental values. The $\left[\mathrm{ZrO}_{2}+\mathrm{BTB}\right]^{\mathrm{C}}$ presents a good candidate for optoelectronics and solar cell applications.
\end{abstract}

Keywords: Nanocomposite $\left[\mathrm{ZrO}_{2}+B T B\right]^{C}, X R D, D F T$, thin films, optical properties

\section{Introduction}

The applications of dye composites in industries have been enhanced quickly due to their unique properties, such as light-in-weight, high stiffness, and high strength. [1-2]. Bromothymol blue $\left(\mathrm{C}_{27} \mathrm{H}_{28} \mathrm{Br}_{2} \mathrm{O}_{5} \mathrm{~S}\right)$ (sometimes known as bromothymol sulfone phthalein, and $\left.\mathrm{BTB}\right)$ is one of the promising candidates for state-of-the-art organic semiconductors, valid for various optoelectronic devices [3]. It is regularly used in applications that need measuring substances that would have a relatively neutral $\mathrm{pH} \cong$ 7 [4,5]. Sulfone phthalein dyes are an essential pH indicator class for some applications in modern sensors [6-7]. For this goal, the sol-gel process has been successfully employed due to its singular versatility and the following characteristics: optic transparency, mechanic stability, chemical resistance, 
and flexibility of sensor morphological configurations [8-10]. Therefore, these materials have potential applications in the pharmaceutical, food, and chemical industries $[11,12]$. Once again, the molecular chemical reactivity of the dye molecules was investigated using DFT-based reactivity descriptors, electrophilicity index (A), chemical potential $(\mu)$, and chemical hardness (A) values were approximated in terms of molecular orbital energy, HOMO and LUMO frontier values [13]. A TD-DFT investigation of ground and excited-state properties in indoline dyes used for dye-sensitized solar cells, the ground and excitedstate properties of three indoline dyes, namely D102, D131, and D149, specially designed for dyesensitized solar cell applications have been studied by the means of density functional theory (DFT) and time-dependent DFT (TD-DFT) and compared with experimental absorption and fluorescence spectra [14].

Sulfonphthaleine dyes are an essential $\mathrm{pH}$ indicator class for certain applications in new sensors. A theoretical analysis to elucidate the impact of physical factors on the sulfonphthalein dyes halochromic behavior. Sulfonphthaleine dyes are phenol red, cresol red, bromophenol blue, and consideration are given to physical factors such as temperature, strain, solvent dielectric constant, and the form of constituent atoms isotope. Meanwhile, variations in $\mathrm{pH}$ of indicator color change, i.e. $\mathrm{pH}$, are studied with the indicators' physical factors in the acid-base equilibrium. These findings show the significance of physical factors on the halochromic activity of colorants for further study and the production of $\mathrm{pH}$ sensors [15].

At the same time, environmentally friendly nano regime materials were developed for the past few years with the aim of low-cost production using simple green technologies. Nano zirconia $\left[\mathrm{ZrO}_{2}\right]^{\mathrm{NPs}}$ are widely used in various photocatalytic, piezoelectric applications, as a catalyst in various organic reactions [16] and industries for ceramics, dental, and optical coatings [17,18]. The cytotoxic activity of nanoparticles mainly depends on its size and shape [19,20]. Various chemical methods such as the solvothermal method, hydrothermal method [21-25], aqueous precipitation method [26], sol-gel method [27-29], thermal decomposition methods [30-32] and pyrolysis of zirconium oxychloride salt organic precursors have been applied to prepare $\mathrm{ZrO}_{2} \mathrm{NPs}$ [33]. These methods are more effective for controlling the shape and size of nanoparticles but often results in the formation of mixed crystal phases [34-36]. However, all these methods require high temperature, costly, and environmentally hazardous chemical precursors during synthesis processes [37-38].

In this work, a novel synthesizes $\left[\mathrm{ZrO}_{2}+\mathrm{BTB}\right]^{\mathrm{C}}$ to study the structural and optical properties of the fabricated nanocomposite thin films has been carried out. Also, study the molecular structure of $\left[\mathrm{ZrO}_{2}+\mathrm{BTB}\right]^{\mathrm{C}}$ using FTIR and molecular electrostatic potential (MEP) techniques. Also, the configuration and morphology description of the $\left[\mathrm{ZrO}_{2}+\mathrm{BTB}\right]^{\mathrm{C}}$ using XRD and SEM techniques will be 
studied. Finally, the optical properties of the fabricated film have been carried out. Simulated measurements of the optical properties were also conducted for $\left[\mathrm{ZrO}_{2}+\mathrm{BTB}\right]^{\mathrm{C}}$ as-deposited films by CATSTEP in the DFT method.

\section{Experimental tools and measurements:}

\subsection{Materials}

The list of chemicals used in conducting the current experiments is presented in Table 1. All chemicals were utilized as received without supplementary refinement.

Table 1. List of chemicals used and their molecular formulas

\begin{tabular}{lll}
\hline Chemical & Molecular formula & \multicolumn{1}{c}{ Supplier } \\
\hline Bromothymol blue (BTB) & $\mathrm{C}_{27} \mathrm{H}_{28} \mathrm{Br}_{2} \mathrm{O}_{5} \mathrm{~S}$ & (Aldrich Chemical Co. Ltd) \\
Zirconium nitrate & $\mathrm{Zr}_{2}\left(\mathrm{NO}_{3}\right)_{4}$ & BDH \\
Oxalic Acid & $\mathrm{C}_{2} \mathrm{H}_{2} \mathrm{O}_{4} .2 \mathrm{H}_{2} \mathrm{O}$ & LOBA Chemie, India \\
Ethanol & $\mathrm{C}_{2} \mathrm{H}_{5} \mathrm{OH}$ & Aldrich \\
Anhydrous dimethyl formaldehyde (DMF) & $\mathrm{C}_{3} \mathrm{H}_{7} \mathrm{NO}$ & Merck \\
Dimethyl sulfoxide & $\mathrm{C}_{2} \mathrm{H}_{6} \mathrm{SO}$ & Merck \\
Hydrochloric and Hydrofluoric acid & $\mathrm{HCl}$ and HF & Sigma \&Aldrich \\
Single crystal of p-Si & p-type & \\
Perchloric acid) and Nitric acid & $\mathrm{HClO}_{4}$ and $\mathrm{HNO}_{3}$ & Merck \\
\hline
\end{tabular}

\subsection{Fabrication of $\left[\mathrm{ZrO}_{2}-\mathrm{BTB}\right]^{\mathrm{C}}$}

To synthesize zirconium nanoparticles $\left[\mathrm{ZnO}_{2}\right]^{\mathrm{NPs}}, 1.0 \mathrm{M}$ solution was prepared by dissolving $15.43 \mathrm{~g}$ of high purity zirconium (IV) nitrate in $100 \mathrm{ml}$ double-distilled (DD) water under magnetic stirring. Another $1.5 \mathrm{M}$ solution was prepared by dissolving $18.91 \mathrm{~g}$ of high purity oxalic acid in $100 \mathrm{ml} \mathrm{DD}$ water. This second solution was added into the first one and the stirring continued for $2 \mathrm{~h}$ at $50{ }^{\circ} \mathrm{C}$. The mixed solution was aged for $10 \mathrm{~h}$ at room temperature (RT) then stirred at $80{ }^{\circ} \mathrm{C}$ for $30 \mathrm{~min}$ [39]. $0.5 \mathrm{~g} \mathrm{BTB}$ was dissolved in $25 \mathrm{ml} \mathrm{DD}$ water/ethanol (50:50\%) at 50 ${ }^{\circ} \mathrm{C}$ and magnetic stirring for $1 \mathrm{~h}$ till the complete dissolution of BTB. The homogenous BTB solution was doped with the prepared sol-gel $\left[\mathrm{ZrO}_{2}\right]^{\mathrm{NPs}}$ at ratio $W=0.5 \% w t$. using the equation: $W(w t . \%)=\left[\frac{w_{Z r O 2 N P S}}{w_{B T B}+w_{Z r O 2 N P S}}\right] \times 100$ where $w_{Z n O 2 N P S}$ and $w_{B T B}$ is the $\left[\mathrm{ZrO}_{2}\right]^{\mathrm{NPs}}$ and BTB weights, respectively. Finally, the solutions were cast into cleaned glass Petri dishes and placed in an oven to dry at $60{ }^{\circ} \mathrm{C}$ for $24 \mathrm{~h}$ in air. The homogenous solution was peeled off from the Petri dishes and care was taken to obtain the polymer thin film $\left[\mathrm{ZrO}_{2}-\mathrm{BTB}\right]^{\mathrm{C}}$ of uniform thickness. Finally, $\left[\mathrm{ZrO}_{2}-\mathrm{BTB}\right]^{\mathrm{C}}$ was kept in zipper bags to prevent humidity influence.

\subsection{Characterization}

Characterization methods and typical conditions are listed in Table 2.

Table 2. List of characterization methods. 


\begin{tabular}{|c|c|}
\hline Characterization method & Model used and specifications \\
\hline FT-IR & $\begin{array}{l}\text { Perkin-Elmer FT-IR type } 1650 \text { spectrophotometer (wavelength range } 4000- \\
200 \mathrm{~cm}^{-1} \text { ). }\end{array}$ \\
\hline XRD & $\begin{array}{l}\text { Philips X-ray diffractometer (model X'pert) with monochromatic } \mathrm{Cu} \mathrm{K \alpha} \\
\text { radiation operated at } 40 \mathrm{kV} \text { and } 25 \mathrm{~mA} \text {. }\end{array}$ \\
\hline SEM & $\begin{array}{l}\text { Scanning Electron Microscopy (SEM; Inspect S, FEI, Holland), operated at } \\
\text { an accelerating voltage of } 3.0 \mathrm{kV}\end{array}$ \\
\hline Thermal Evaporator & Edwards type E 306 A, England \\
\hline Film thickness & Model FTM4. Edwards, England \\
\hline UV & SHIMADZU UV-3101 UV-vis-NIR pc. \\
\hline
\end{tabular}

\section{Results and discussions}

Scheme 1 summarizes the reaction of [BTB] ethanolic solution with $\left[\mathrm{ZrO}_{2}\right]^{\mathrm{NPs}}$ to form $\left[\mathrm{ZrO}_{2}+\mathrm{BTB}\right]^{\mathrm{C}}$ compound. Mechanism of reaction between $[\mathrm{BTB}]$ in $(50: 50 \mathrm{v} / \mathrm{v})$ aqueous/ethanolic solution with $\left[\mathrm{ZrO}_{2}\right]^{\mathrm{NPs}}$ by using a spin coating (Sol-Gel Method) for the formation and decomposition [40]. The reaction of $\left[\mathrm{ZrO}_{2}\right]^{\mathrm{NPs}}$ with $\mathrm{BTB}$ is shown in Scheme 1 to form the novel $\left[\mathrm{ZrO}_{2}+\mathrm{BTB}\right]^{\mathrm{C}}$ nanocomposite.
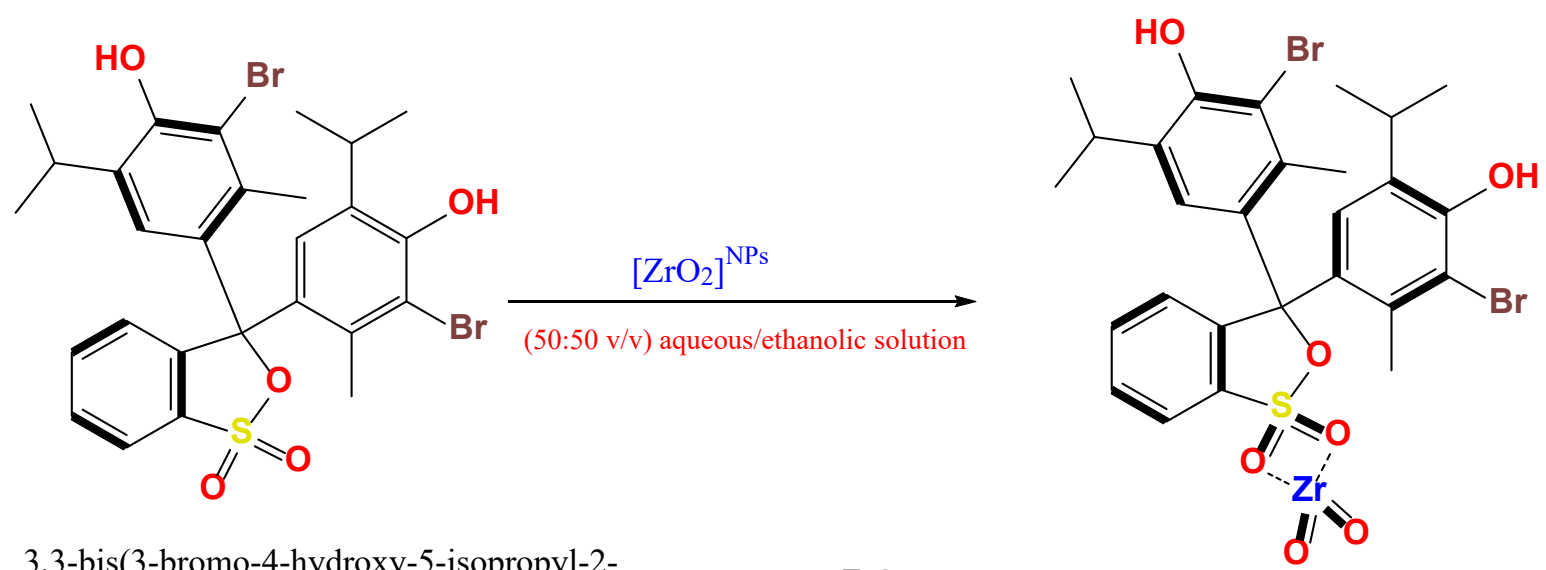

3,3-bis(3-bromo-4-hydroxy-5-isopropyl-2methylphenyl)-3H-benzo[c][1,2] oxathiole 1,1dioxide [BTB]

$\mathrm{ZrO}_{2}$-3,3-bis(3-bromo-4-hydroxy-5-isopropyl-2-methylphenyl
benzo[c][1,2] oxathiole 1,1-dioxide $\left[\mathbf{Z r O}_{2}-\mathbf{B T B}\right]^{\mathbf{C}}$

Scheme 1. The mechanism formation of $\left[\mathrm{ZrO}_{2}+\mathrm{BTB}\right]^{\mathrm{C}}$

\subsection{Fourier Transform Infrared Spectroscopy (FT-IR)}

FT-IR reveals chemical changes to the structure of the dye and nanocomposite. Fig. 1 and Fig. 2 show the experimental and simulation IR spectrum of [BTB] and $\left[\mathrm{ZrO}_{2}+\mathrm{BTB}\right]^{\mathrm{C}}$, respectively [41]. In the experimental spectrum (Fig.1) for both $[\mathrm{BTB}]$ and $\left[\mathrm{ZrO}_{2}+\mathrm{BTB}\right]^{\mathrm{C}}$, a strong absorption band was detected at $3400 \mathrm{~cm}^{-1}$ which can be attributed to stretching hydroxide group in BTB dye $\mathrm{v}(\mathrm{OH})$ and intra- water molecular vibration $(\mathrm{vOH})$ for both $[\mathrm{BTB}]$ and $\left[\mathrm{ZrO}_{2}+\mathrm{BTB}\right]^{\mathrm{C}}$, respectively [42-43]. The bands at 2960 $\mathrm{cm}^{-1}$ and $2868 \mathrm{~cm}^{-1}$ due to $(\mathrm{v}-\mathrm{H})$ stretching of alkane in benzene ring for both $[\mathrm{BTB}]$ and $\left[\mathrm{ZrO}_{2}+\mathrm{BTB}\right]^{\mathrm{C}}$. Bands at $1605 \mathrm{~cm}^{-1}$ and $1472 \mathrm{~cm}^{-1}$ were allocated to $\mathrm{C}-\mathrm{H}$ bond stretching and bending vibrations $\left(v_{\mathrm{CH}}\right.$ and $\left.\delta_{\mathrm{CH}}\right)$ for both $[\mathrm{BTB}]$ and $\left[\mathrm{ZrO}_{2}+\mathrm{BTB}\right]^{\mathrm{C}}$, respectively [44-45]. In contrast, absorption bands around $1402 \mathrm{~cm}^{-1}, 1193$, and $1160 \mathrm{~cm}^{-1}$, were attributed to antisymmetric $v(\mathrm{o}=\mathrm{S}=\mathrm{O})$ for both [BTB] and 
$\left[\mathrm{ZrO}_{2}+\mathrm{BTB}\right]^{\mathrm{C}}$. Moreover, the bending vibration of the ether (glycosidic) linkage $\delta$ (S-O-C) was designated by a strong peak at $1040 \mathrm{~cm}^{-1}[46]$. The $\left[\mathrm{ZrO}_{2}+\mathrm{BTB}\right]^{\mathrm{C}}$ spectrum (Blue color) presents besides the above bonds a peak that is not found in that of [BTB], particularly at $3480 \mathrm{~cm}^{-1}$ is due to $\mathrm{Zr}-\mathrm{OH}_{2}$ rocking of water. And also, the spectrum of the $\left.\mathrm{ZrO}_{2}+\mathrm{BTB}\right]^{\mathrm{C}}$ exhibit additional FTIR strong bands at 570 $\mathrm{cm}^{-1}, 543 \mathrm{~cm}^{-1}$ and $464 \mathrm{~cm}^{-1}$ assigned to $v(\mathrm{M}-\mathrm{O})$ modes [47].

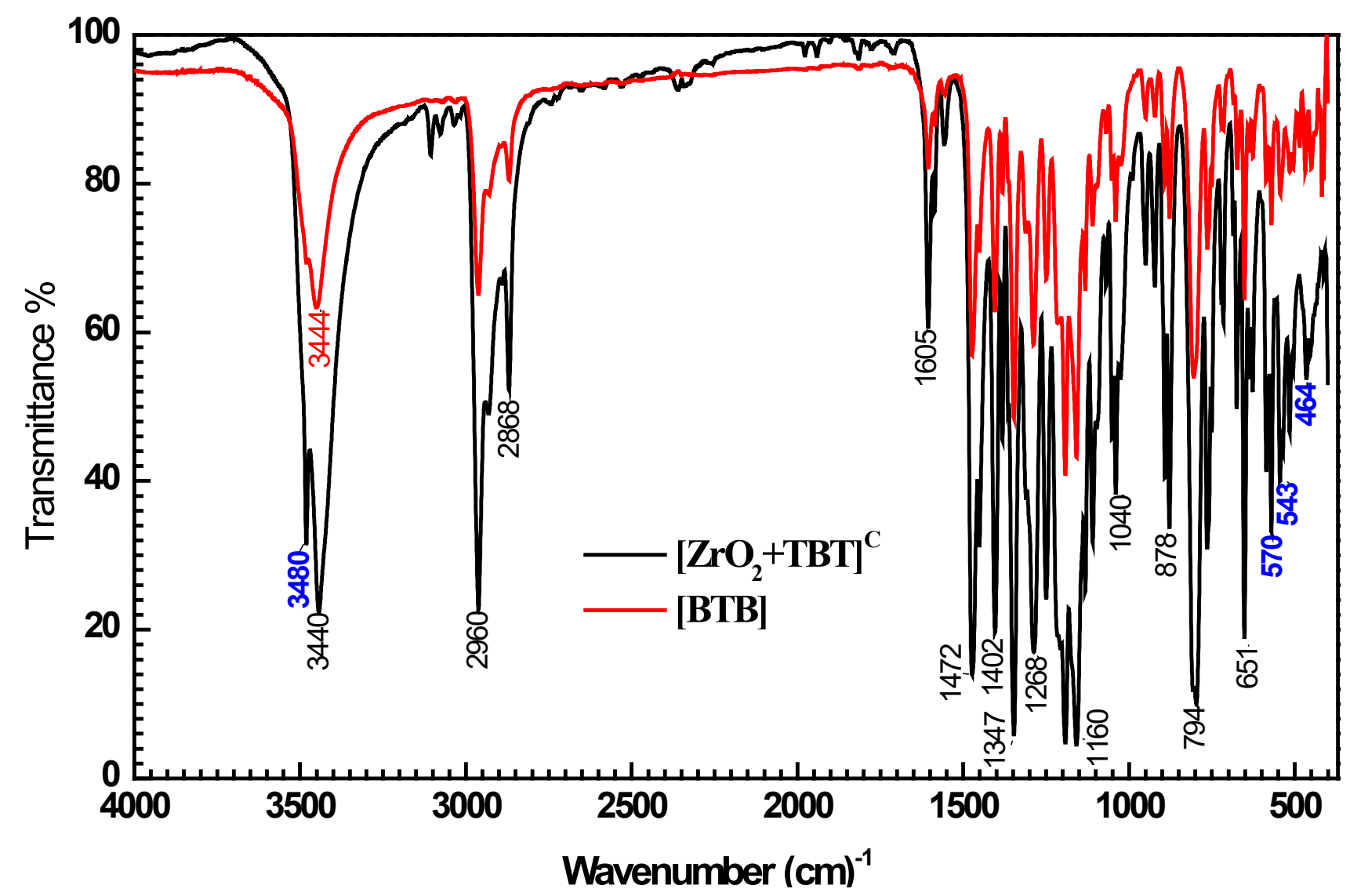

Fig. 1. The FTIR spectra experimental data of $[\mathrm{BTB}]$ and $\left[\mathrm{ZrO}_{2}+\mathrm{BTB}\right]^{\mathrm{C}}$.

The Gaussian simulation spectra for both $[\mathrm{BTB}]$ and $\left[\mathrm{ZrO}_{2}+\mathrm{BTB}\right]^{\mathrm{C}}$ have been studied in an isolated state. A strong absorption bands were detected at range $3600 \mathrm{~cm}^{-1}$ to $3850 \mathrm{~cm}^{-1}$ which can be attributed to intra- water molecular vibration $(\mathrm{vOH})$ for both $[\mathrm{BTB}]$ and $\left[\mathrm{ZrO}_{2}+\mathrm{BTB}\right]^{\mathrm{C}}$. The bands at range $2900-$ $3100 \mathrm{~cm}^{-1}$ were allocated to $\mathrm{C}-\mathrm{H}$ bond stretching and bending vibrations $\left(v_{\mathrm{CH}}\right.$ and $\left.\delta_{\mathrm{CH}}\right)$ for both [BTB] and $\left[\mathrm{ZrO}_{2}+\mathrm{BTB}\right]^{\mathrm{C}}$. this vibration of $v_{\mathrm{CH}}$ and $\delta_{\mathrm{CH}}$ also appear at range $1500-1600 \mathrm{~cm}^{-1}$. In contrast, the absorption bands around at $1200-1300 \mathrm{~cm}^{-1}$ were attributed to antisymmetric ( $\left.v_{\text {C-S-O }}\right)$ for both [BTB] and $\left[\mathrm{ZrO}_{2}+\mathrm{BTB}\right]^{\mathrm{C}}$. The $\left[\mathrm{ZrO}_{2}+\mathrm{BTB}\right]^{\mathrm{C}}$ spectrum presents besides the in above bond peaks that are not found in that of [BTB], particularly at $549 \mathrm{~cm}^{-1} 452 \mathrm{~cm}^{-1}$ which are allocated to metal oxide (Zr-O) [48-49]. 

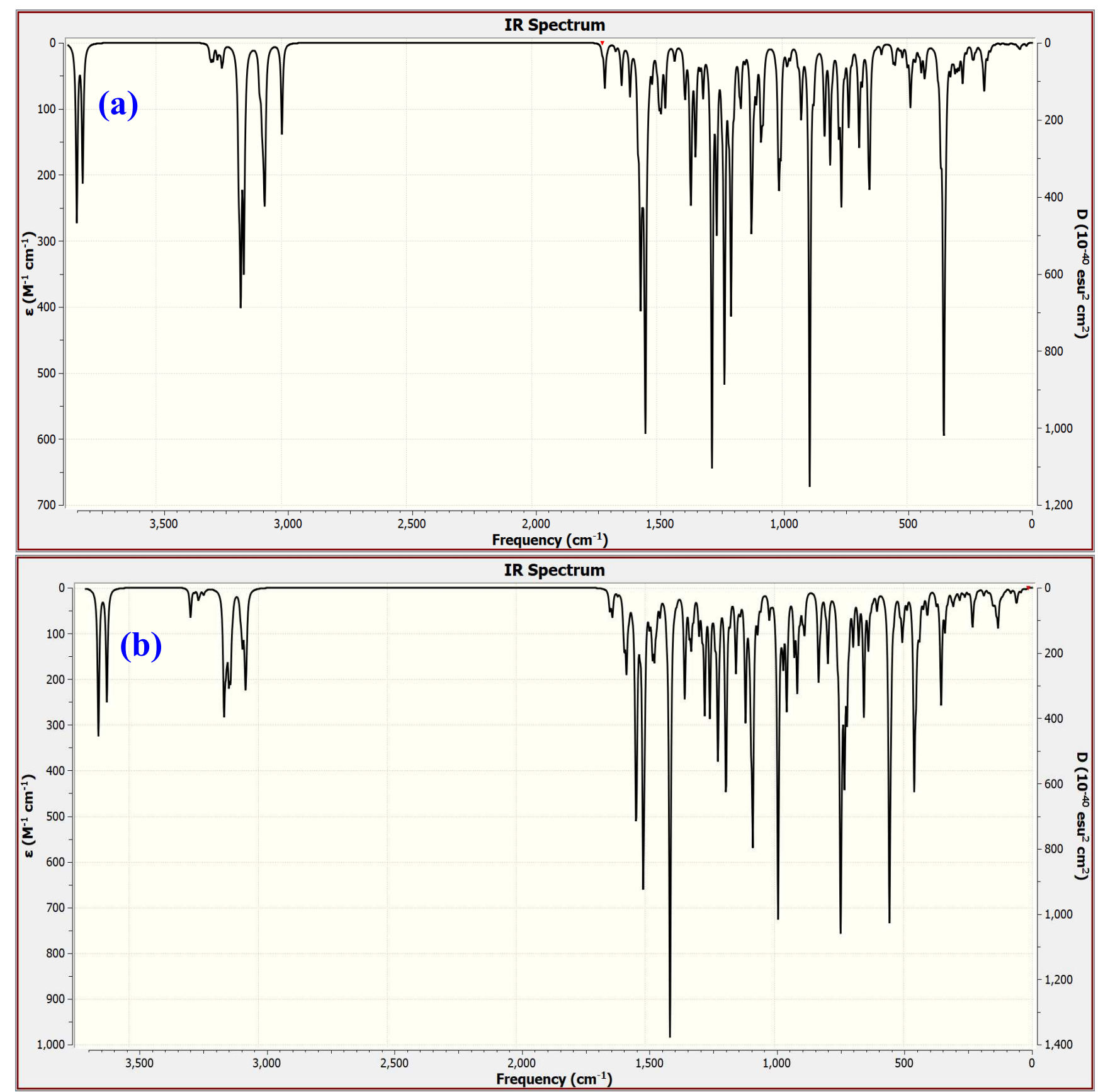

Fig. 2(a-b). The FTIR spectra Gaussian data of $[\mathrm{BTB}]$ and $\left[\mathrm{ZrO}_{2}+\mathrm{BTB}\right]^{\mathrm{C}}$.

It has been concluded that when the comparison between FTIR experimental data for [BTB] and $\left[\mathrm{ZrO}_{2}+\mathrm{BTB}\right]^{\mathrm{C}}$ as thin films (Fig. 1) and IR Gaussian simulation for [BTB] and $\left[\mathrm{ZrO}_{2}+\mathrm{BTB}\right]^{\mathrm{C}}$ as isolated state or gas state (Fig. 2(a-b)) that has a good agreement [50]. These agreements in peak intensities and locations confirmed the formation of the predicted $\left[\mathrm{ZrO}_{2}+\mathrm{BTB}\right]^{\mathrm{C}}$ structure in Scheme 1.

\subsection{XRD}

The X-ray powder diffraction analysis (XRD) is used to identify atomic configurations of orientation and crystalline phases: structure, target direction, change in order-disorder, thermal expansions, and thickness measurements for thin films and multilayer [51-52]. In an XRD study, a diffractogram indicates 
the frequency according to the angle of diffraction. Fig. 3 shows the experimental XRD diffractograms for both $[\mathrm{BTB}]^{\mathrm{TF}}$ and $\left[\mathrm{ZrO}_{2}+\mathrm{BTB}\right]^{\mathrm{C}}$. XRD patterns of $[\mathrm{BTB}]^{\mathrm{TF}}$ polymer show distinguished peaks with $h k l$ at (101) and (200) as semicrystalline powder behavior. However, the XRD pattern of $\left[\mathrm{ZrO}_{2}\right]^{\mathrm{NPs}}$ illustrates several peaks in the range of $4^{\circ}<2 \theta<80^{\circ}$ with $h k l$ at (250), (311), (241) and (712). The high crystallinity and the high order within the sample were identified. The specific distributed signals and the position of the peaks $(2 \theta)$ show also the structure of the organic compound. Finally, the highest peaks in this pattern with $h k l$ can be observed at (101), (200), (250), (311), (241) and (712) corresponding to the crystalline aspect of $\left[\mathrm{ZrO}_{2}+\mathrm{BTB}\right]^{\mathrm{C}}$ nanocomposite.

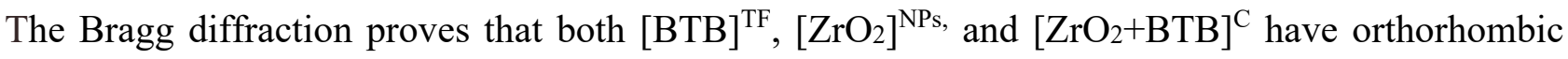
symmetry with different crystalline structure parameters [53-54] tabulated in Table 3. The main cause of this crystallization is probably the introduction of $\left[\mathrm{ZrO}_{2}\right]^{\mathrm{NPs}}$ to $[\mathrm{BTB}]^{\mathrm{TF}}$. The machine error, root mean square deviation (rmse), and orthodromic cell volume of $[\mathrm{BTB}]^{\mathrm{TF}},\left[\mathrm{ZrO}_{2}\right]^{\mathrm{NPs}}$, and $\left[\mathrm{ZrO}{ }_{2}+\mathrm{BTB}\right]^{\mathrm{C}}$ lattices are illustrated in Table 3. The averaged-spacing distance between atomic layers is $2.454 \AA, 2.525 \AA$, and $2.878 \AA$ for $[\mathrm{BTB}]^{\mathrm{TF}},\left[\mathrm{ZrO}_{2}\right]^{\mathrm{NPs}}$, and $\left[\mathrm{ZrO}_{2}+\mathrm{BTB}\right]^{\mathrm{C}}$, respectively. Table 3 provides peak data of $[\mathrm{BTB}]^{\mathrm{TF}}$, $\left[\mathrm{ZrO}_{2}\right]^{\mathrm{NPs}}$, and $\left[\mathrm{ZrO}_{2}+\mathrm{BTB}\right]^{\mathrm{C}}$ using the Bragg equation while the $\mathrm{d}$-spacing for the strongest crystalline signal is calculated with the Debye - Scherrer equation. This equation is $F W H M(2 \theta)=(b \lambda / D \cos \theta)$ in terms of $2 \theta$, where $F W H M$ is the full width of the peak, $2 \theta$ is the scattering angle in radians, $\lambda$ is the wavelength, $b$ is a constant, which normally takes a value between 0.89 and 0.94 depending on the function used to fit the peak, and $D$ is the dimension of the crystallites as if they were cubes, monodisperse in size. Therefore, for different reflections and different crystallite shapes, the interpretation of $D$ must be treated with some care. For polydisperse systems, $D$ is a measure of the volume-averaged crystallite size. Thus, the $[\mathrm{BTB}]^{\mathrm{TF}},\left[\mathrm{ZrO}_{2}\right]^{\mathrm{NPs}}$ and $\left[\mathrm{ZrO}_{2}+\mathrm{BTB}\right]^{\mathrm{C}}$ average crystallite size are $D_{a v}=31.63 \mathrm{~nm}, D_{a v}=23.74 \mathrm{~nm}$ and $D_{a v}=18.21 \mathrm{~nm}$, respectively. This decrease in the average crystallite size of $\left[\mathrm{ZrO}_{2}+\mathrm{BTB}\right]^{\mathrm{C}}$ indicates a relatively low graphitization degree even after treatment and correlates. The simulation data conducted using Crystal Sleuth software (Program REFINE Version 3.0) Kurt Barthelme's and Bob Downs) and material studio software (PMP predict) is in great compliance with experimental XRD patterns (Fig. 4) [55]. 


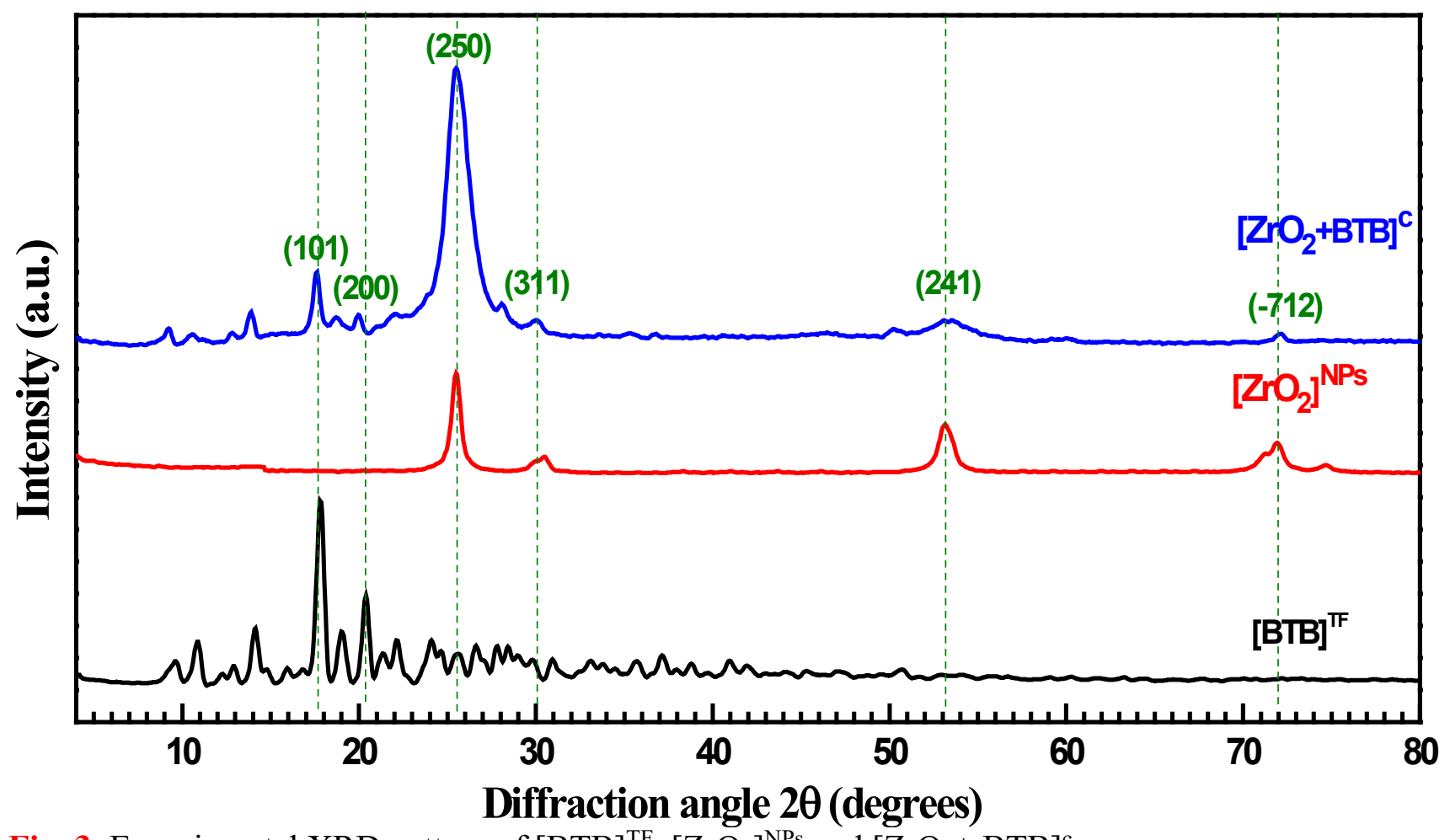

Fig. 3. Experimental XRD pattern of $[\mathrm{BTB}]^{\mathrm{TF}},\left[\mathrm{ZrO}_{2}\right]^{\mathrm{NPs}}$ and $\left[\mathrm{ZrO}_{2}+\mathrm{BTB}\right]^{\mathrm{c}}$

Table 3. **Program REFINE Version 3.0** Kurt Barthelme's and Bob Downs, 1998

\begin{tabular}{lcccccccccc}
\hline Symmetry constraint & \multicolumn{3}{c}{ Observed } & \multicolumn{2}{c}{ Calculated } & \multicolumn{2}{c}{ Difference } & FWHM & \multicolumn{2}{c}{$\mathrm{I}^{\prime} \mathrm{I}_{0}$} \\
& $2 \theta^{\circ}$ & $\mathrm{d}$ & $\mathrm{hkl}$ & $2 \theta^{\circ}$ & $\mathrm{d}$ & $2 \theta^{\circ}$ & $\mathrm{d}$ & $\mathrm{nm}$ & $\mathrm{nm}$ \\
\hline Orthorhombic & & & & & & & & & \\
$\lambda=1.540562 \AA$ & 17.58 & 5.021 & 101 & 17.595 & 5.017 & 0.0153 & 0.00431 & 0.5221 & 566.469 \\
$\mathrm{a}=7.38(5) ; \mathrm{b}=18.178(6) ;$ & 19.94 & 4.434 & 200 & 19.912 & 4.440 & -0.029 & -0.0064 & 0.3783 & 147.929 \\
$\mathrm{c}=26.10(3) \AA$ & 25.58 & 3.471 & 250 & 25.623 & 3.465 & 0.0480 & 0.00637 & 1.8643 & 2453.73 \\
$\alpha=\beta=\gamma=90^{\circ}$ & 29.89 & 2.979 & 311 & 29.852 & 2.984 & -0.0416 & -0.0041 & 1.4424 & 169.990 \\
rmse $=0.00027552729$ & 53.34 & 1.714 & 241 & 53.351 & 1.714 & 0.0096 & 0.00028 & 2.6100 & 145.047 \\
Machine error $=0.068$ & 72.01 & 1.309 & $\overline{7} 12$ & 72.008 & 1.309 & -0.0030 & -0.0001 & 0.7071 & 86.5590 \\
Volume $=5300(27)$ & & & & & & & & &
\end{tabular}

Using the Materials Studio and Crystal Sleuth software results, the unit cell lattice parameters (a, b, $\mathrm{c}, \alpha, \beta$ and $\gamma$ ) and space group $\left(\mathrm{P} 6_{1}\right)$ of $[\mathrm{BTB}]^{\mathrm{TF}},\left[\mathrm{ZrO}_{2}\right]^{\mathrm{NPs}}$, and $\left[\mathrm{ZrO}_{2}+\mathrm{BTB}\right]^{\mathrm{c}}$ are tabulated in Table 3 . The first step in the simulation was the preparation of the $[\mathrm{BTB}]^{\mathrm{TF}}$ and $\left[\mathrm{ZrO}_{2}+\mathrm{BTB}\right]^{\mathrm{c}}$ layers. The free ligand $[\mathrm{BTB}]^{\mathrm{TF}}$ and $\left[\mathrm{ZrO}_{2}\right]^{\mathrm{NPs}}$ layers of $\left[\mathrm{ZrO}_{2}+\mathrm{BTB}\right]^{\mathrm{c}}$ were constructed using atomic coordinates from the previously reported crystal structure of the American Mineralogist Crystal Structure Database [5657], whose X-ray crystal structure had been refined in an orthorhombic. The differences are not significant when one considers that the reported uncertainties are those of the fit, not including any effects arising from systematic errors. 


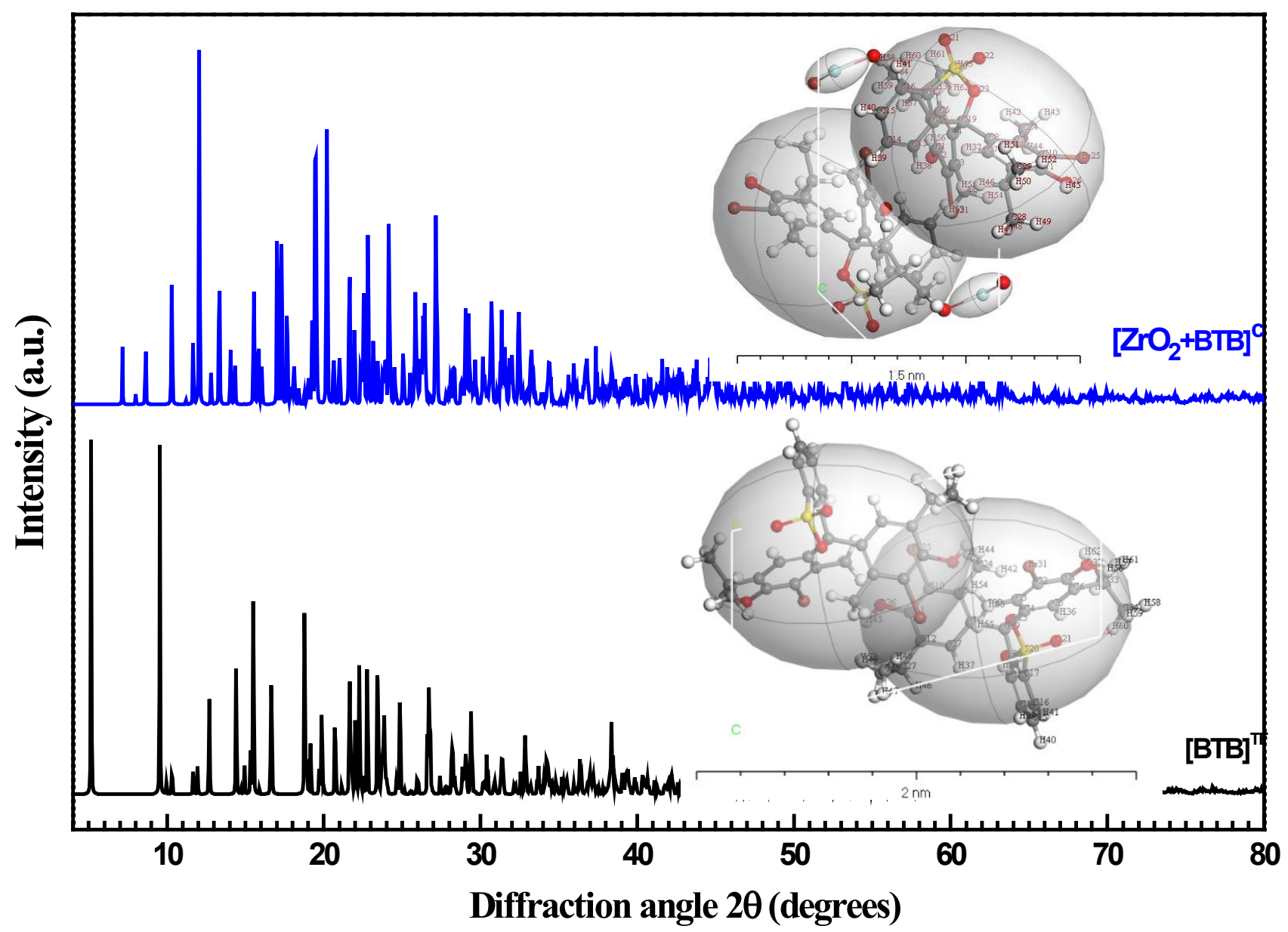

Fig. 4. Simulation XRD pattern of $[\mathrm{BTB}]^{\mathrm{TF}}$ and $\left[\mathrm{ZrO}_{2}+\mathrm{BTB}\right]^{\mathrm{c}}$ by using Material Studio.

\subsection{SEM}

Quantitative structural characterization was carried out using SEM images of the fabricated nanocomposite materials. Topographic features of both $[\mathrm{BTB}]^{\mathrm{TF}}$ and $\left[\mathrm{ZrO}_{2}+\mathrm{BTB}\right]^{\mathrm{c}}$ as-deposited thin films (150 nm thickness), by using SEM images, were studied as shown in Fig. 5(a-b). As seen in Fig. $5 \mathrm{a}$, the as-obtained films of $[\mathrm{BTB}]^{\mathrm{TF}}$ prepared by the Sol-Gel method aggregated easily and formed nano spherical aggregates. The average calculated value of particle size by SEM images for $[\mathrm{BTB}]^{\mathrm{TF}}$ spherical films is $35 \pm 5 \mathrm{~nm}$, which coincides with that obtained by XRD measurements. On the other hand, Fig. $5 b$ displays SEM images of $\left[\mathrm{ZrO}_{2}+\mathrm{BTB}\right]^{\mathrm{c}}$ as-deposited thin films. Image of $\left[\mathrm{ZrO}_{2}+\mathrm{BTB}\right]^{\mathrm{c}}$ shows a onedimensional morphological structure with arranged, densely packed fibrous nanowires (i.e, like rods shapes) or brush such as a uniform structure was grown. By using the image j software program, Fig. 5b shows a long-range uniformity of the nanowires with an average thickness of $\cong 0.45 \mu \mathrm{m} \pm 15 \mathrm{~nm}$ and the length in the range $\cong 4.12 \mu \mathrm{m} \pm 38 \mathrm{~nm}$ for.

A larger surface region is accorded by microfiber structures resulting from the synthesis of the nanocomposite thin films. The fabrication of $\left[\mathrm{ZrO}_{2}+\mathrm{BTB}\right]^{\mathrm{c}}$ microfibers derives from a self-assembling process of co- $\left[\mathrm{ZrO}_{2}\right]^{\mathrm{NPs}}-[\mathrm{BTB}]^{\mathrm{TF}}$ units, which contain $\pi$-type bonds. Clarification for the process of 
self-assembling as reported by [58-61], which consider both the intermolecular $\pi \rightarrow \pi^{*}$ interactions with the hydrogen bonds linked between $\left[\mathrm{ZrO}_{2}\right]^{\mathrm{NPs}}-[\mathrm{BTB}]^{\mathrm{TF}}$ chains.
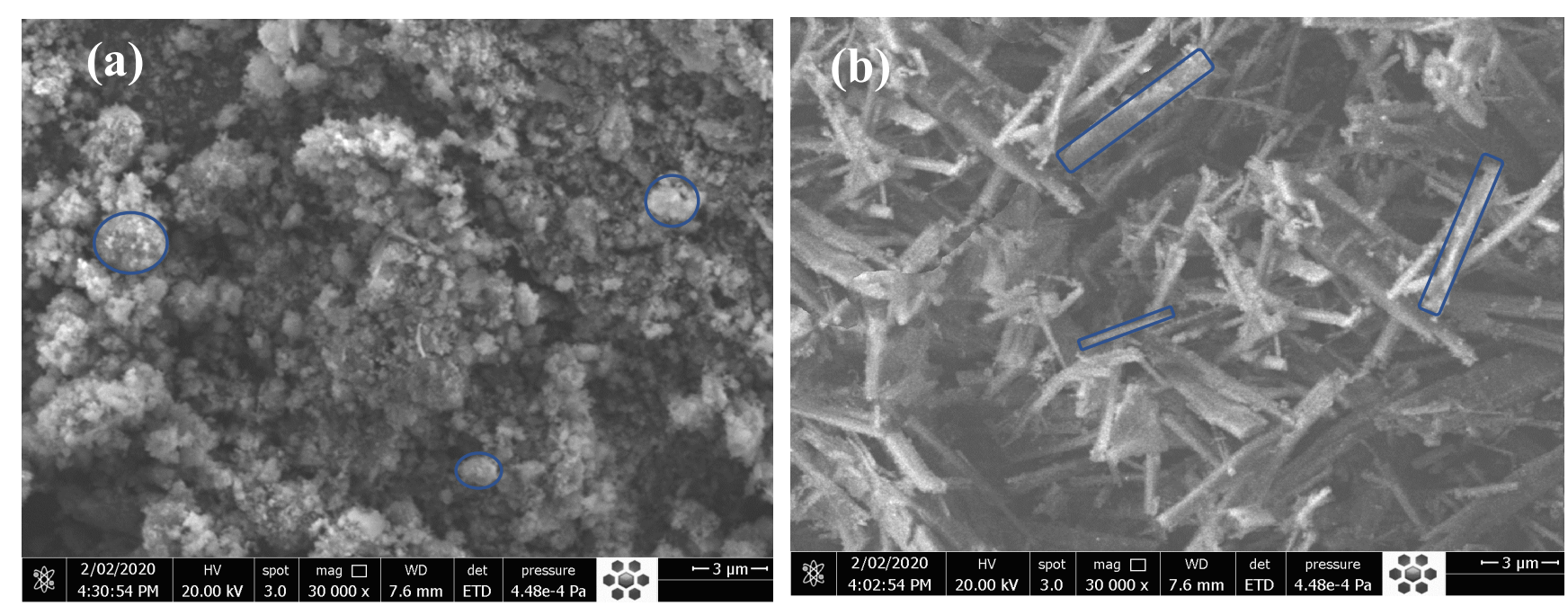

Fig. 5 Top view of the prepared $[\mathrm{BTB}]^{\mathrm{TF}}$ and $\left[\mathrm{ZrO}_{2}+\mathrm{BTB}\right]^{\mathrm{C}}$ thin films $(150 \mathrm{~nm})$ using the SEM technique.

\subsection{Molecular electrostatic potential (MEP), electron density (ED) and Potential of [BTB] and $\left[\mathrm{ZrO}_{2}+\mathrm{BTB}\right]^{\mathrm{C}}$.}

The active location of MEP is displayed by a 3D illustration in Fig. 6(a) and Fig. 6(d) for [BTB] and $\left[\mathrm{ZrO}_{2}+\mathrm{BTB}\right]^{\mathrm{C}}$, respectively. The blue color constitutes the propitious zone for the nucleophilic attack, while the propitious zone for electrophilic attacks is constituted by a red color. The potential range [P] of the matrix $\mathrm{BTB}$ and $\left[\mathrm{ZrO}_{2}+\mathrm{BTB}\right]^{\mathrm{C}}$ in the isolated molecule and crystal models are $-6.553 \times 10^{-2} \geq[\mathrm{P}] \geq$ $6.523 \times 10^{-2}$ and $-7.063 \times 10^{-2} \geq[\mathrm{P}] \geq 7.063 \times 10^{-2}$, respectively, while the increase follows the order: red $<$ brown $<$ blue [62]. The blue color is the largest attraction, whereas the red color is a powerful repudiation. The diagram of the MEP reveals that nitrogen electronegative atoms reflect the regions of negative potential and hydrogen atoms have a positive potential [63]. The chemical and physical similarities of $[\mathrm{BTB}]$ and $\left[\mathrm{ZrO}_{2}+\mathrm{BTB}\right]^{\mathrm{C}}$ have been investigated by utilizing the electron density and the electrostatic potential. The basic principle of DFT Fig. 6(a) and Fig. 6(d), the use of electron density as the essential factor to define the ground state of many-electron systems is further discussed for [BTB] and $\left[\mathrm{ZrO}_{2}+\mathrm{BTB}\right]^{\mathrm{C}}$, respectively. The potential possible diagrams of $[\mathrm{BTB}]$ and $\left[\mathrm{ZrO}_{2}+\mathrm{BTB}\right]^{\mathrm{C}}$ (Fig. $6(\mathrm{~b})$ and Fig. 6(e)), the potential growth of $[\mathrm{BTB}]$ is shown to be lower than that of $\left[\mathrm{ZrO}_{2}+\mathrm{BTB}\right]^{\mathrm{C}}$. This indicates an increased probability of electron transition in $\left[\mathrm{ZrO}_{2}+\mathrm{BTB}\right]^{\mathrm{C}}$. The MEP has been used to describe the electrostatic potential depending on the constant electron density surface. 

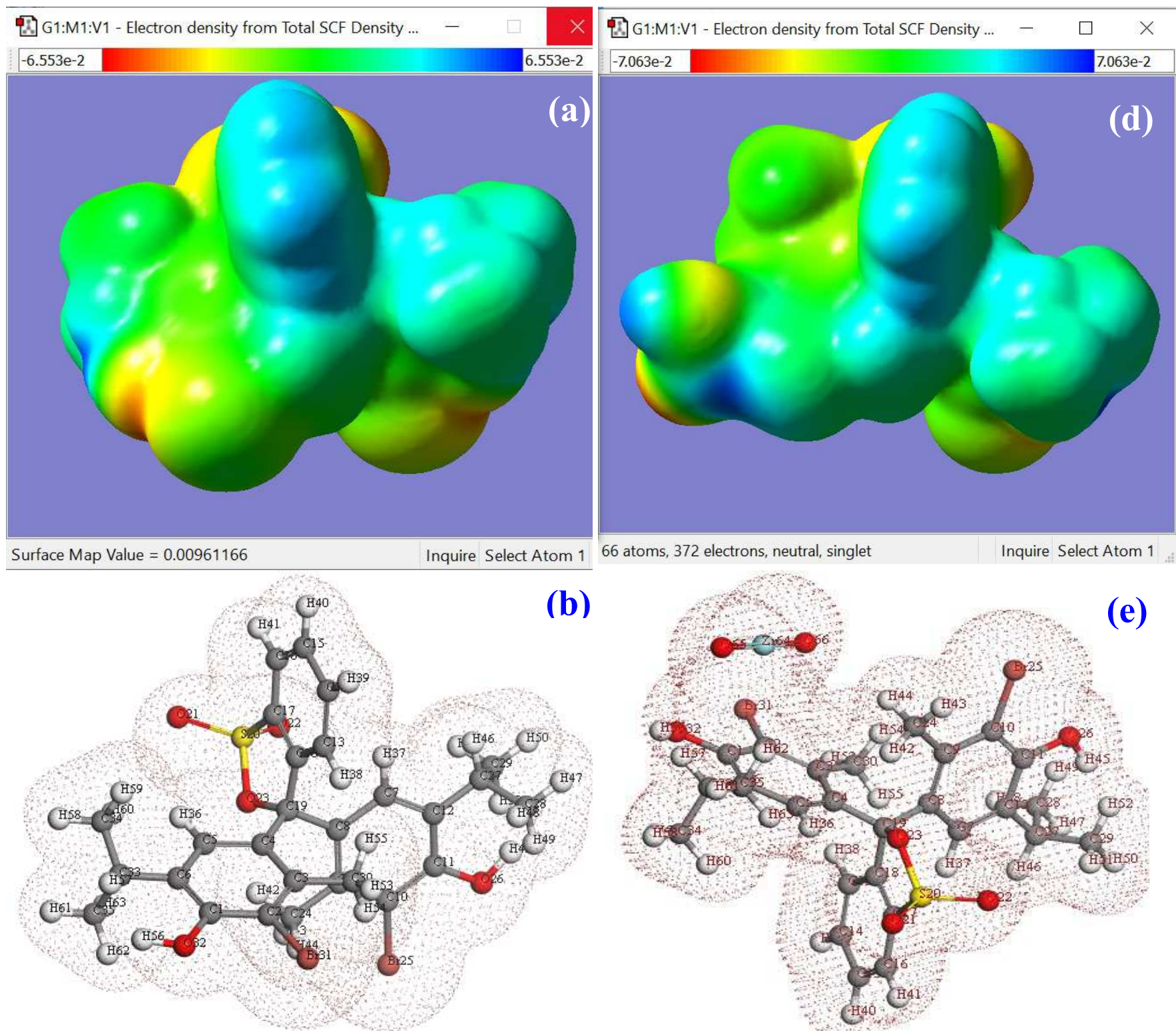

(e)
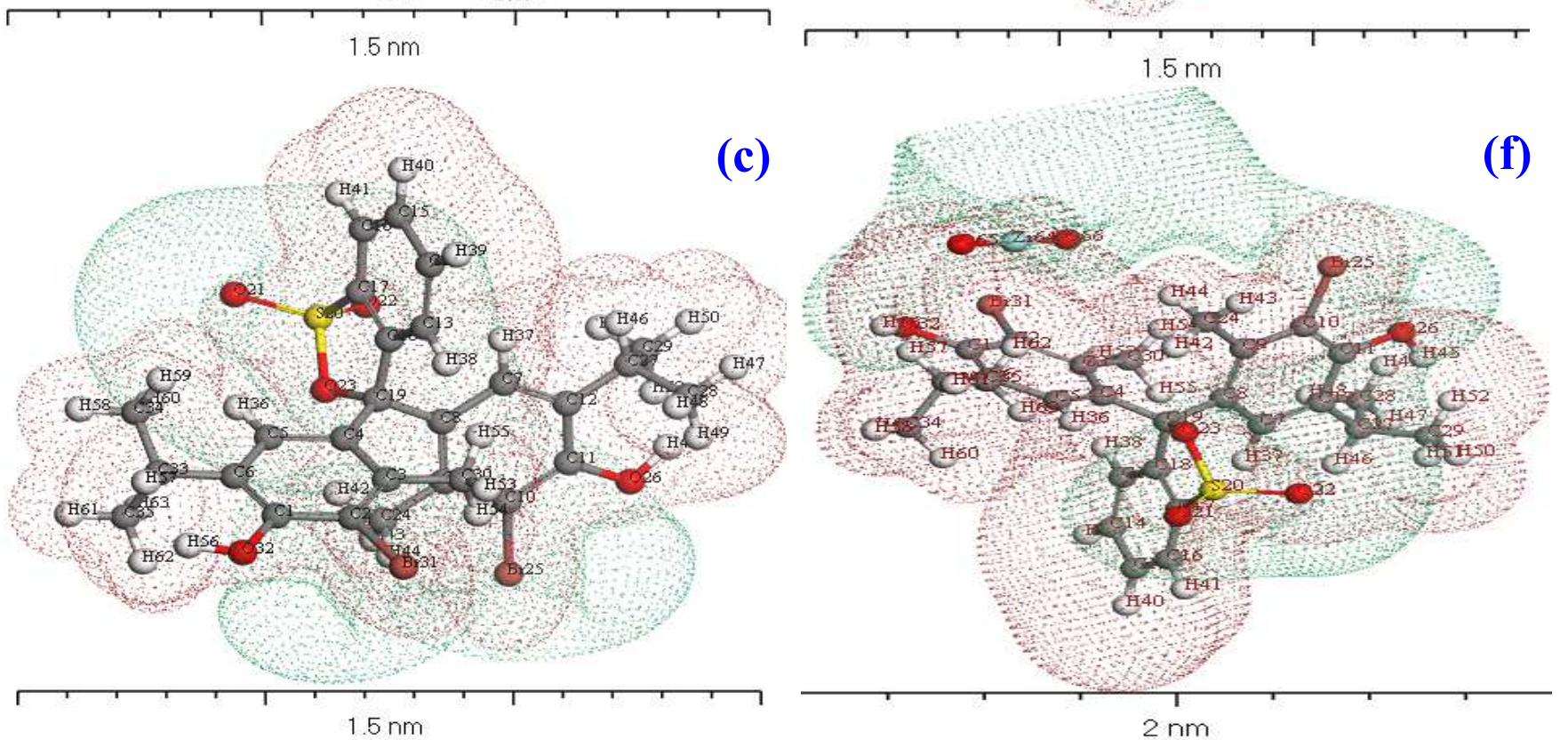

Fig. 6 a) MEP of [BTB]; b) Electron density of [BTB] ; c) Potential of [BTB], d) MEP of $\left[\mathrm{ZrO}_{2}+\mathrm{BTB}\right]^{\mathrm{C}}$; e) Electron density of $\left[\mathrm{ZrO}_{2}+\mathrm{BTB}\right]^{\mathrm{C}}$ and e) Potential of $\left[\mathrm{ZrO}_{2}+\mathrm{BTB}\right]^{\mathrm{C}}$ by using DFT calculation in material studio and Gaussian software programs 


\subsection{Optical properties of both $[\mathrm{BTB}]^{\mathrm{TF}}$ and $\left[\mathrm{ZrO}_{2}+\mathrm{BTB}\right]^{\mathrm{C}}$ thin films}

UV-Vis spectroscopy indicates absorbent spectroscopy in this region of spectra. Since the atoms and molecules experience electronic transformations in the ultraviolet-visible region of the spectrum. Both bromothymol blue $[\mathrm{BTB}]^{\mathrm{TF}}$ and $\left[\mathrm{ZrO}_{2}+\mathrm{BTB}\right]^{\mathrm{C}}$ thin films were more validated by UV-Vis absorption spectroscopy as shown in Fig. 7. The spectra measurements for $[\mathrm{BTB}]^{\mathrm{TF}}$ and the hybrid $\left[\mathrm{ZrO}_{2}+\mathrm{BTB}\right]^{\mathrm{C}}$ were measured using a spectrophotometer at room temperature in the wavelength range as $250 \mathrm{~nm} \leq$ $\lambda \leq 700 \mathrm{~nm}$. The spectra of all features of $[\mathrm{BTB}]^{\mathrm{TF}}$ thin-film discover three bands of absorption at 280, 328 , and $422 \mathrm{~nm}$, respectively. The band of $\lambda_{\max }=422 \mathrm{~nm}$ is the maximum broadband (i.e, the core band of BTB) of a wavelength region ranged from $360 \mathrm{~nm}<\lambda<550 \mathrm{~nm}$.

Also, Fig. 7 shows the UV-Vis absorption spectrum for the hybrid nanocomposite of $\left[\mathrm{ZrO}_{2}+\mathrm{BTB}\right] \mathrm{C}$ thin film. The spectrum is characterized by three band peaks, but with a double value of absorbance. This may be due to the $\mathrm{ZrO}_{2}$ molecules. Since adding the $\mathrm{ZrO}_{2}$ in the [BTB] dye matrix increases the peak strength. There is therefore a chemical reaction between the two components in the matrix, and the increase in absorption is due to the increase in the percentage of $\mathrm{ZrO}_{2}$, which is the absorbing component.

Moreover, there are no shifts in first and second band peaks maximum wavelengths (i.e, $\lambda$ max. are $280 \mathrm{~nm}$ and $328 \mathrm{~nm}$ ). While the third band peak has been divided into two sharp peaks with $\lambda \max$ equal to $416 \mathrm{~nm}$ and $422 \mathrm{~nm}$, respectively. The three absorption peaks at about 280, 328, and $422 \mathrm{~nm}$ are attributed to the electrons transition from the highest occupied molecular orbital (HOMO) to the lowest unoccupied molecular orbital LUMO, which is related to $\pi \rightarrow \pi^{*}$ electronic transition for both [BTB] ${ }^{\mathrm{TF}}$ and $\left[\mathrm{ZrO}_{2}+\mathrm{BTB}\right]^{\mathrm{C}}[64-68]$.

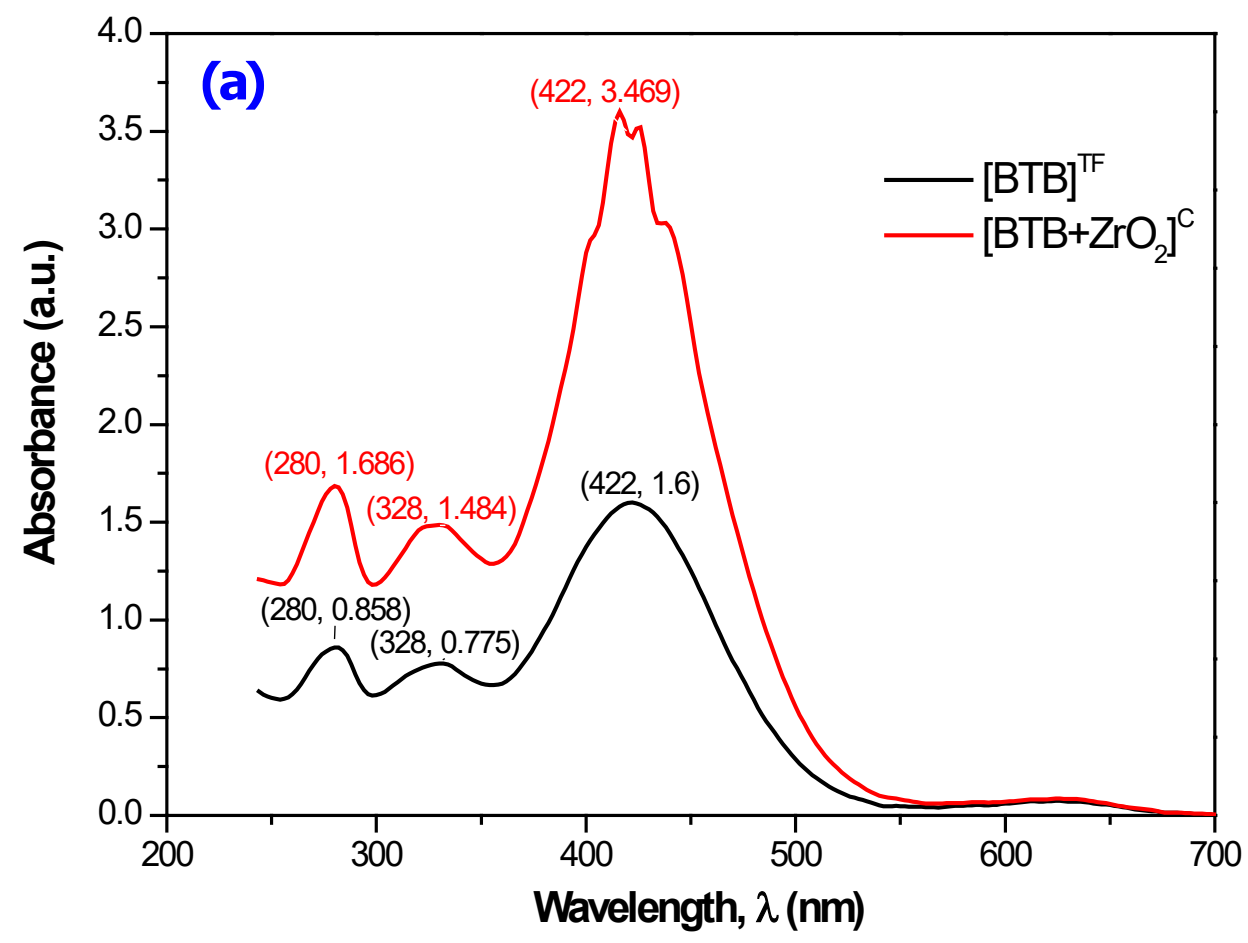


Fig.7 a) UV-vis absorption spectra of $[\mathrm{BTB}]^{\mathrm{TF}}$ and $\left[\mathrm{ZrO}_{2}+\mathrm{BTB}\right]^{\mathrm{C}}$

\subsection{Energy gaps calculations by Tauc's and DFT simulation}

The calculated energy bandgap $\left(E_{g}\right)$ of the $[\mathrm{BTB}]^{\mathrm{TF}}$ and $\left[\mathrm{ZrO}_{2}+\mathrm{BTB}\right]^{\mathrm{C}}$ were computed with the help of absorption spectra. The Tauc's relation is employed to compute the $E_{g}$ values from absorption spectra:

$$
(\alpha h v)^{m}=A\left(h v-E_{g}\right)
$$

Where $\mathrm{A}$ is independent energy constant and $\mathrm{h} v$ is the energy of incident photons and $\mathrm{m}=1 / 2$ and 2 for $\operatorname{direct}\left(E_{g}^{d i r}\right)$ and indirectly allowed $\left(E_{g}^{\text {ind }}\right)$ transitions. The $E_{g}^{d i r}$ and $E_{g}^{\text {ind }}$ transitions for the $[\mathrm{BTB}]^{\mathrm{TF}}$ and $\left[\mathrm{ZrO}_{2}+\mathrm{BTB}\right]^{\mathrm{C}}$ nanocomposite thin films were computed by utilizing Eq. (1). Fig. 8(a-b) shows the plot of $(\alpha h v)^{0.5} \times 10^{3}(\mathrm{eV} / \mathrm{m})^{0.5}$ versus photon energy $h v(\mathrm{eV})$, for both [BTB] ${ }^{\mathrm{TF}}$ and a mixture of $\left[\mathrm{ZrO}_{2}+\mathrm{BTB}\right]^{\mathrm{C}}[\mathrm{BTB}]$ thin films (Thickness $150 \pm 5 \mathrm{~nm}$ ) [69]. At higher photon energies, the relationship between $(\alpha h v)^{2}$ or $(\alpha h v)^{0.5}$ and $(h v)$ are depicted in Fig. 8(a and b)), which denotes that direct and indirect optical transitions are likely for both $[\mathrm{BTB}]^{\mathrm{TF}}$ and $\left[\mathrm{ZrO}_{2}+\mathrm{BTB}\right]^{\mathrm{C}}$ films. The straight-line portions of these

curves are extrapolated to zero to compute the actual value of optical band gaps, $E_{g}^{\text {ind }}$ and $E_{g}^{\text {ind }}$ are $(2.251$ and $2.252 \mathrm{eV})$ and $(2.596$ and $2.649 \mathrm{eV})$ for both $[\mathrm{BTB}]^{\mathrm{TF}}$ and $\left[\mathrm{ZrO}_{2}+\mathrm{BTB}\right]^{\mathrm{C}}$ film, respectively.

The values of $E_{g}^{\text {ind }}$ of the $[\mathrm{BTB}]^{\mathrm{TF}}$ is $2.251 \mathrm{eV}$, nearly the same for $\left[\mathrm{ZrO}_{2}+\mathrm{BTB}\right]^{\mathrm{C}}$ with $2.252 \mathrm{eV}$ as depicted in Fig. 8(a). Fabrication of $\left[\mathrm{ZrO}_{2}+\mathrm{BTB}\right]^{\mathrm{C}}$ nanocomposite thin films may introduce energy levels inside the bandgap. The same behavior is also observed for $E_{g}^{d i r}$, which increased from 2.596 $\left([\mathrm{BTB}]^{\mathrm{TF}}\right)$ to $2.649 \mathrm{eV}$ after fabricating $\left[\mathrm{ZrO}_{2}+\mathrm{BTB}\right]^{\mathrm{C}}$ nanocomposite film. 


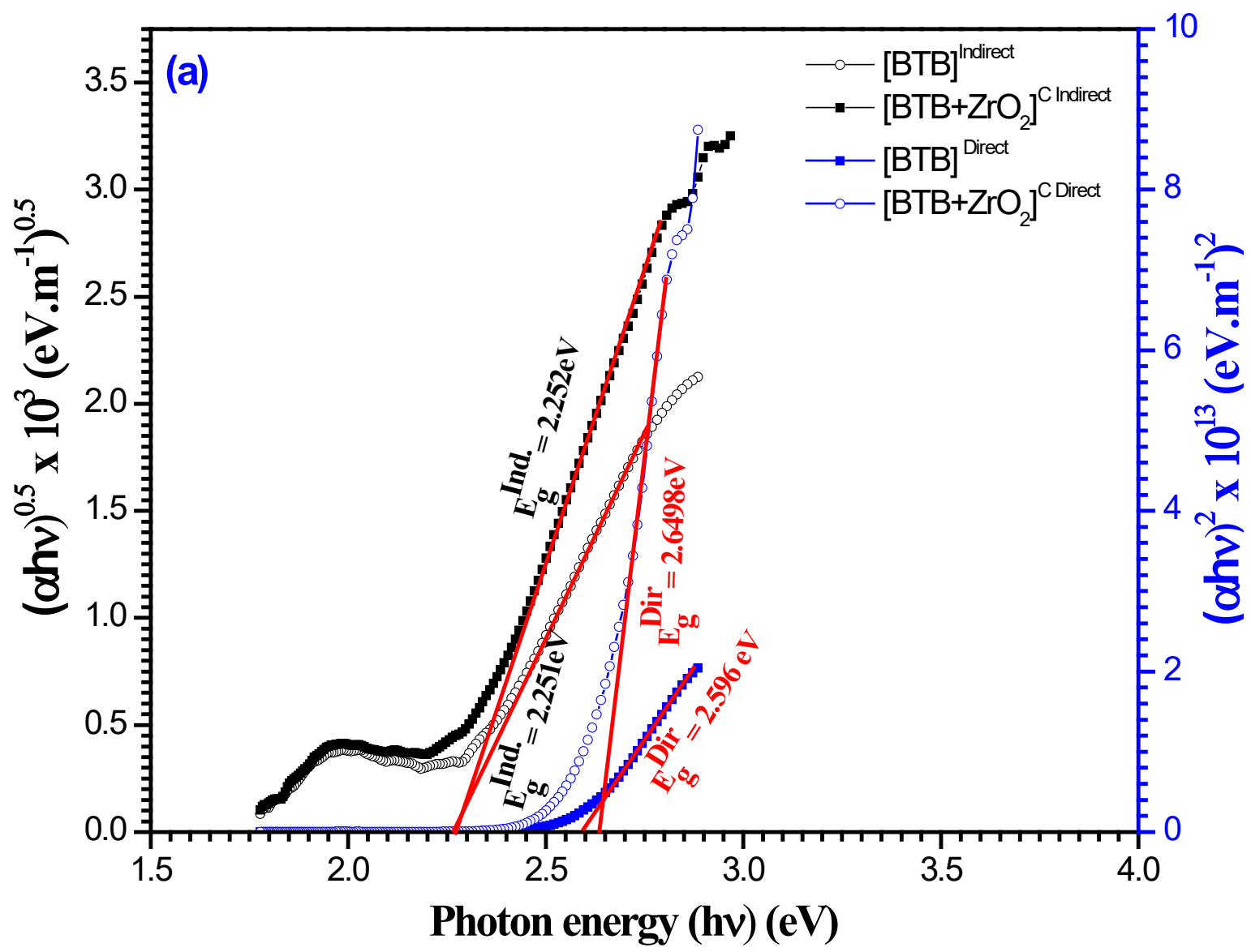

(b)

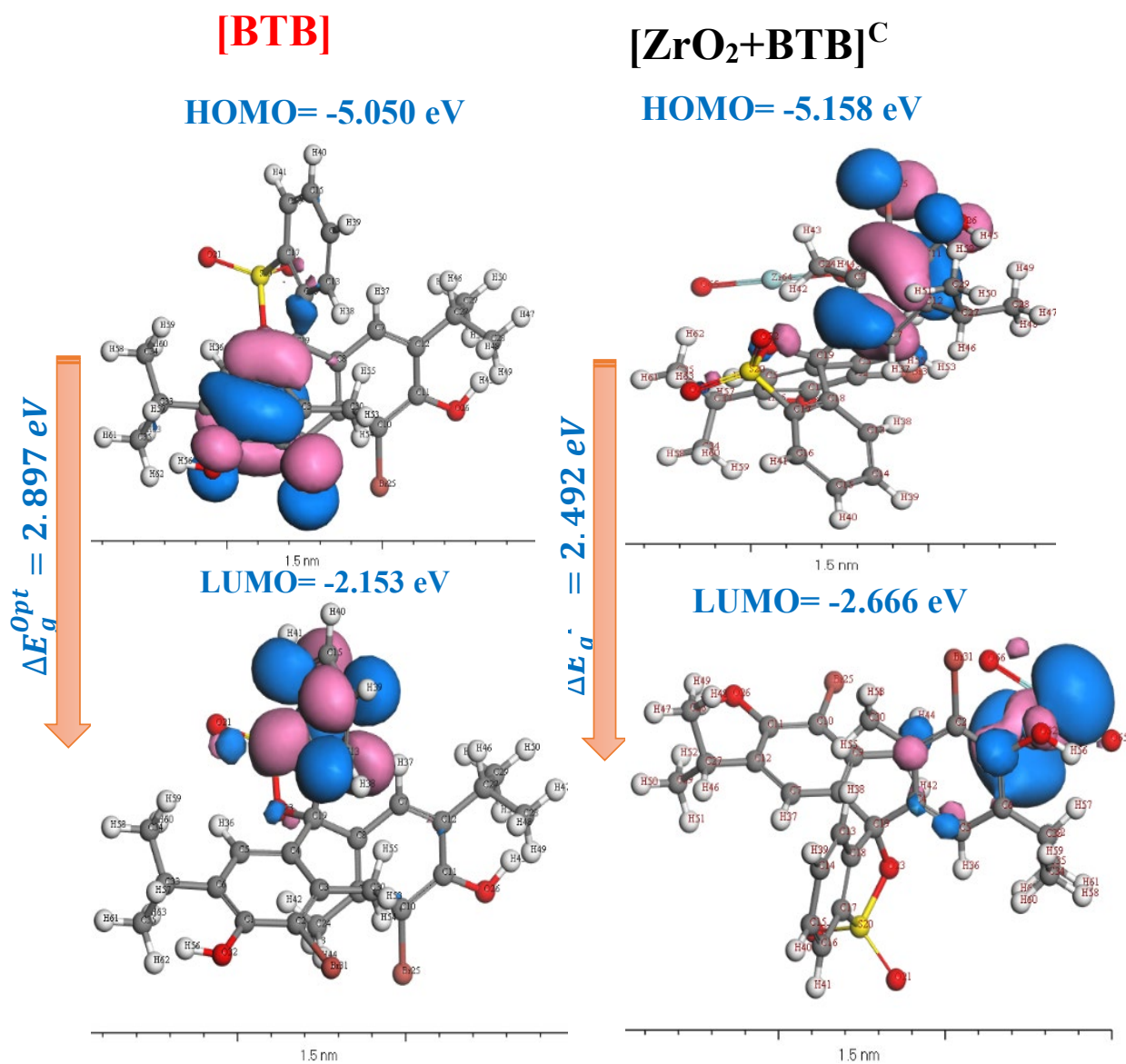

Fig.8 a) The computed band gaps of $[\mathrm{BTB}]^{\mathrm{TF}}$ and $\left[\mathrm{ZrO}_{2}+\mathrm{BTB}\right]^{\mathrm{C}}$ using Tauc's equation. b) Figure is computed HOMO and LUMO using DFT by DMol${ }^{3}$. 
Fig. 8(b) shows the DFT/CASTEP program geometry optimization technique used density functional theory (DFT) to estimate direct gap widths of for both $[\mathrm{BTB}]^{\mathrm{TF}}$ and $\left[\mathrm{ZrO}_{2}+\mathrm{BTB}\right]^{\mathrm{C}}$. The values of $\Delta E_{g}^{o p t .}=$ $2.897 \mathrm{eV}$ and $2.492 \mathrm{eV}$ for $[\mathrm{BTB}]^{\mathrm{TF}}$ and $\left[\mathrm{ZrO}_{2}+\mathrm{BTB}\right]^{\mathrm{C}}$, respectively. Since, $\Delta E_{g}^{o p t}$. is defined as the lower energy value and is assigned to Frankel-exciton generation or a bound electron-hole pair [70-71] is calculated from the difference between HOMO and LUMO by using the $\mathrm{DMol}^{3}$ method in DFT as shown in Fig. 8(b). The energy gap between the HOMO and LUMO is a critical parameter determining the electronic, optical, redox, and transport (electrical) properties of the $[\mathrm{BTB}]^{\mathrm{TF}}$ and $\left[\mathrm{ZrO}_{2}+\mathrm{BTB}\right]^{\mathrm{C}}$ thin films. In comparison with experimental values, the simulated values are very near to the DFT/CASTEP geometry optimization method values acquired by using DFT. Comparing experimental with simulated CASTEP data for the energy gap $\Delta E_{g}^{o p t}$. found that the variation value between the experimental and simulated values of both $[\mathrm{BTB}]^{\mathrm{TF}}$ and $\left[\mathrm{ZrO}_{2}+\mathrm{BTB}\right]^{\mathrm{C}}$. Therefore, simulated CASTEP data and Tauc's model can be utilized effectively to determine $\Delta E_{g}^{o p t}$. and the electronic transition type, respectively. The difference between the experimental and simulated CASTEP data of the optical energy gap of both $[\mathrm{BTB}]^{\mathrm{TF}}$ and $\left[\mathrm{ZrO}_{2}+\mathrm{BTB}\right]^{\mathrm{C}}$ thin films are $\Delta E_{g}^{\text {opt. }}=0.646 \mathrm{eV}$ (Indirect) and $\Delta E_{g}^{\text {opt. }}=$ $0.301 \mathrm{eV}\left(\right.$ Direct) for $[\mathrm{BTB}]^{\mathrm{TF}}$. And also, the $\Delta E_{g}^{\text {opt }}$ values are $0.645 \mathrm{eV}$ (Indirect) and $0.157 \mathrm{eV}$ (Direct) for $\left[\mathrm{ZrO}_{2}+\mathrm{BTB}\right]^{\mathrm{C}}$ thin films.

\subsection{Optical Dispersion constants}

Polymers, dyes, and organic/inorganic compounds are of great importance in the creation of nanomaterials and other equipment such as optoelectronic devices or solar cells. The refractive index $n(\lambda)$ and extinction coefficient $\mathrm{k}(\lambda)$ values, which included both refraction and absorption based on the interaction between the material being studied and the light-incident. $n(\lambda)$ has a phase velocity correlation with the dispersion, while $\mathrm{k}(\lambda)$ is linked to a mass reduction coefficient and permits the computation of the electromagnetic wave dissipation rate material. The spectroscopic reflectometry measurement of transmission and reflectance permits the $n(\lambda)$ and $k(\lambda)$ versus photon energy (hv) has been studied. 


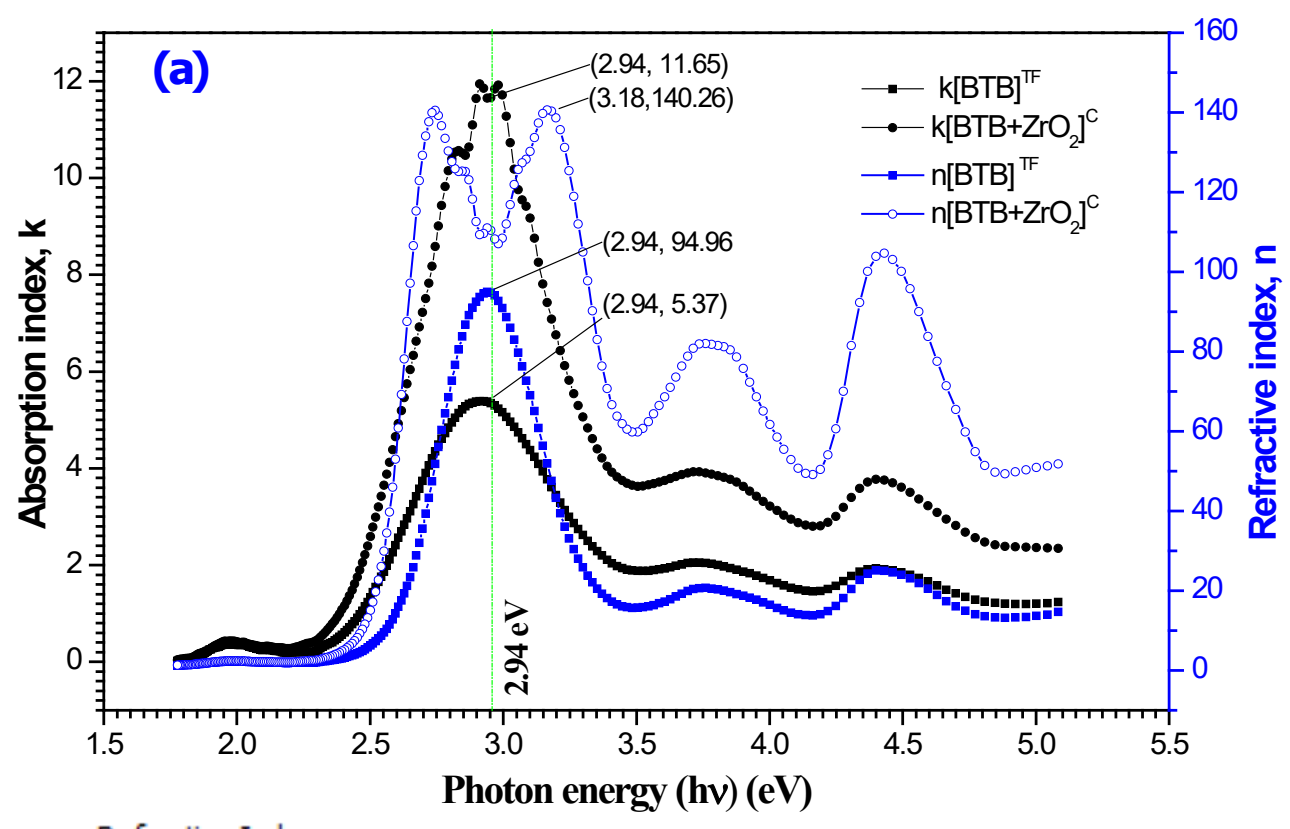

Refractive Index

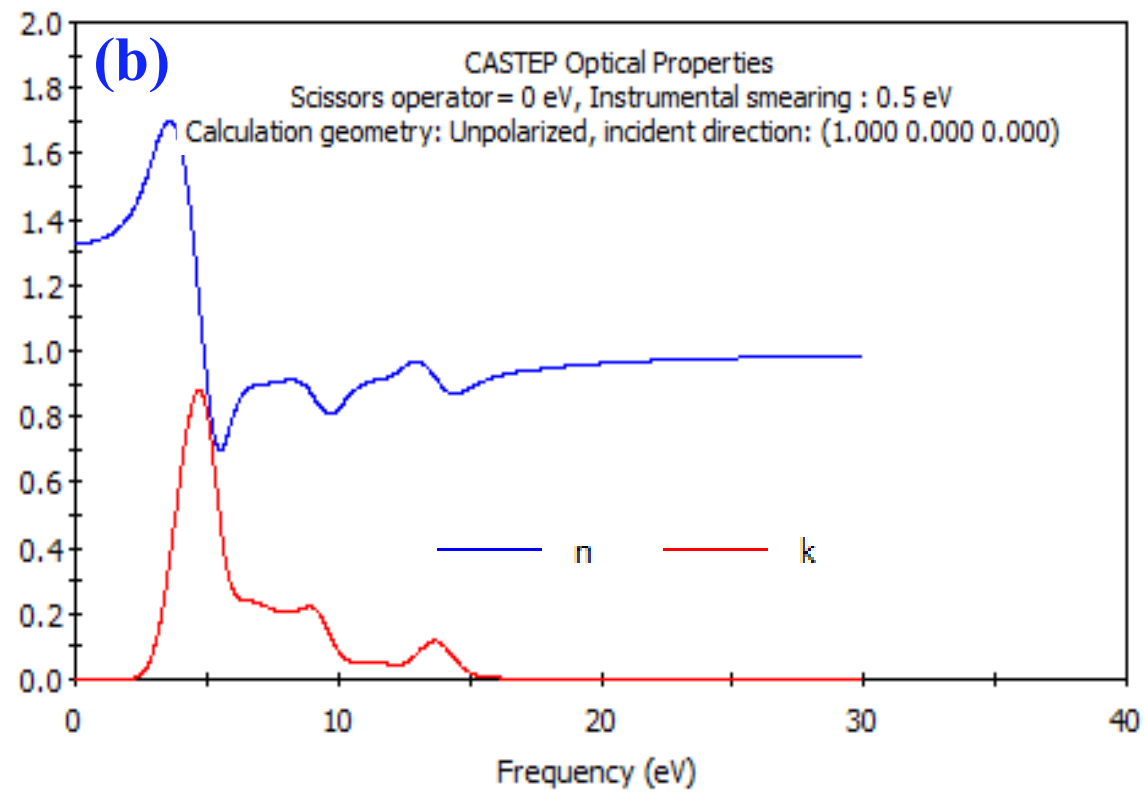

Refractive Index

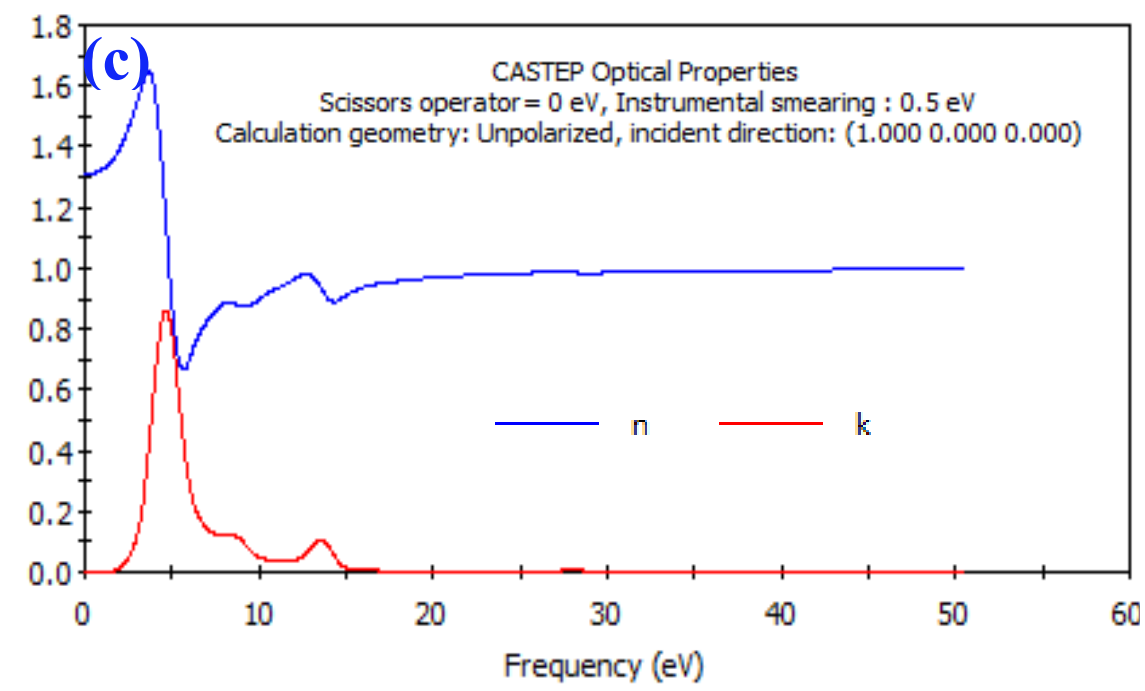

Fig.9 a) The spectral dependence of both the absorption index $k(\lambda)$ and the refractive index $n(\lambda)$ as a function of $h v(e V)$ for $[\mathrm{BTB}]^{\mathrm{TF}}$ and $\left[\mathrm{ZrO}_{2}+\mathrm{BTB}\right]^{\mathrm{C}}$. b-c) Simulated [BTB] and $\left[\mathrm{ZrO}_{2}+\mathrm{BTB}\right]^{\mathrm{C}}$ using CATSTEP optical properties, respectively. 
The spectral properties of $\mathrm{n}(\lambda)$ and $\mathrm{k}(\lambda)$ versus $(h v)$ values for $[\mathrm{BTB}]^{\mathrm{TF}},\left[\mathrm{ZrO}_{2}+\mathrm{BTB}\right]^{\mathrm{C}}$ asdeposited thin films (thickness $150 \mathrm{~nm}$ ) over a range 1.0-5.5 eV of ( $h v)$ are given in Fig. 9(a-b). Where the mathematical formula of both $n(\lambda)$ and $k(\lambda)$ is given by Eqs. (2) and (3) [72] as follows:

$$
\begin{gathered}
n(\lambda)=\left(\frac{1+R}{1-R}\right)+\sqrt{\left[\frac{4 R}{(1-R)^{2}}\right]-k^{2}} \\
k(\lambda)=\frac{\alpha \lambda}{4 \pi} \quad \text { and } \quad \alpha=\frac{1}{d} \ln \left[\frac{(1-R)^{2}}{2 T}+\sqrt{\frac{(1-R)^{4}}{4 T^{2}}+R^{2}}\right]
\end{gathered}
$$

As observed from Fig. 9(a), both $\mathrm{n}(\lambda)$ and $\mathrm{k}(\lambda)$ show similar spectral behavior to each other in the photon energy range from $1.0 \mathrm{eV} \leq h v \leq 5.5 \mathrm{eV}$. Since both $\mathrm{n}(\lambda)$ and $\mathrm{k}(\lambda)$ spectral behaviors depend on the type of material. We can classify the patterns into two parts: (i) the first part in $2.25 \mathrm{eV} \leq h v \leq$ $3.45 \mathrm{eV}$ represents the main characteristic broad peak. For $[\mathrm{BTB}]^{\mathrm{TF}}$ as-deposited film $\mathrm{n}(\lambda)$ pattern shows a maximum peak of $n_{\max }(=9.490)$ at $h v=2.94 \mathrm{eV}$, while $\mathrm{n}(\lambda)$ for $\left[\mathrm{ZrO}_{2}+\mathrm{BTB}\right]^{\mathrm{C}}$ film the spectral behavior has been splitting into two peaks with $\left\{\left(\right.\right.$ i.e, $n_{\max }(=14.026)$ at $\left.h v=2.55 \mathrm{eV}\right)$ and $n_{\max }$. $(=14.026)$ at $h v=3.18 \mathrm{eV})$ for the first and second peaks respectively $\}$. Regarding $\mathrm{k}(\lambda)$ parameter in the range, $2.25 \mathrm{eV} \leq h v \leq 3.45 \mathrm{eV}$ is characterized by a sharp peak with $\left(k_{\max }=1.165\right.$ at $\left.h v=2.94 \mathrm{eV}\right)$. (ii) second part in the photon energy $h v>3.45 \mathrm{eV}$ is characterized by another two broad peaks for both $[\mathrm{BTB}]^{\mathrm{TF}}$ and $\left[\mathrm{ZrO}_{2}+\mathrm{BTB}\right]^{\mathrm{C}}$ as-deposited thin films. Where, $n_{\max }\left(1^{\text {st }}\right.$ peak $)$ are 1.81 and 8.0 at $h v=$ $3.72 \mathrm{eV}$ for $[\mathrm{BTB}]^{\mathrm{TF}}$ and $\left[\mathrm{ZrO}_{2}+\mathrm{BTB}\right]^{\mathrm{C}}$ respectively. While, $n_{\max }$. $\left(2^{\text {nd }}\right.$ peak) are 2.01 and 12.0 at $(h v=$ $4.41 \mathrm{eV})$ for $[\mathrm{BTB}]^{\mathrm{TF}}$ and $\left[\mathrm{ZrO}_{2}+\mathrm{BTB}\right]^{\mathrm{C}}$ respectively. On the other hand, $k_{\max }\left(1^{\text {st }}\right.$ and $2^{\text {nd }}$ peaks $)$ are $0.20(h v=3.72 \mathrm{eV})$ and $0.41(h v=4.41 \mathrm{eV})$ for $[\mathrm{BTB}]^{\mathrm{TF}}$ and $\left[\mathrm{ZrO}_{2}+\mathrm{BTB}\right]^{\mathrm{C}}$ respectively. These obtained maximum peaks were attributed to the $\pi \rightarrow \pi *$ transition due to the presence of benzenoid rings [73-74]. CASTEP method in DFT calculations of $[\mathrm{BTB}]^{\mathrm{TF}}$ and $\left[\mathrm{ZrO}_{2}+\mathrm{BTB}\right]^{\mathrm{C}}$ as- single crystal was utilized to predict $\mathrm{n}(\lambda)$ and $\mathrm{k}(\lambda)$ values (Fig. 9-b). It is also important to note that the simulation curve presents an approximate similarity for $\mathrm{n}(\lambda)$ and $\mathrm{k}(\lambda)$ with a shift towards the highest energies with lower peak intensities. The maximum peaks obtained for $\mathrm{n}(\lambda)$ and $\mathrm{k}(\lambda)$ are obtained $h v \cong 4.15-4.50 \mathrm{eV}$.

\subsection{Dielectric constants and optical conductivity}

Complex dielectric function $\left(\varepsilon^{*}\right)$ is related to both $\mathrm{n}(\lambda)$ and $\mathrm{k}(\lambda)$ as $[75,76]$ :

$$
n(\lambda)+i k(\lambda)=\sqrt{\varepsilon^{*}}
$$

Where the real and imaginary parts of $\varepsilon^{*}$ are $\varepsilon_{1}(\lambda)$ and $\varepsilon_{2}(\lambda)$, respectively. The real dielectric constant $\left(\varepsilon_{1}(\lambda)\right)$ generally relates to dispersion, while the imaginary dielectric constant $\left(\varepsilon_{2}(\lambda)\right)$ provides a measure to the dissipative rate of the wave in the medium [77]. Also, it indicates the loss of energy in 
a dielectric material through conduction slow polarization currents and other dissipative phenomena. Where the loss factor expressed by the ratio $\varepsilon_{2}(\lambda) / \varepsilon_{1}(\lambda)$. Both $\varepsilon_{1}(\lambda)$, and $\varepsilon_{2}(\lambda)$ are evaluated using the relation [78]:

$$
\varepsilon_{1}(\lambda)=n^{2}-k^{2} \text { and } \quad \varepsilon_{2}(\lambda)=2 n k
$$

Fig. 10(a-c) show the spectra of $\varepsilon_{1}(\lambda)$ and $\varepsilon_{2}(\lambda)$ as a function of photon energy experimentally and simulated by using the CASTEP method in DFT for as-deposited $[\mathrm{BTB}]^{\mathrm{TF}}$ and $\left[\mathrm{ZrO}_{2}+\mathrm{BTB}\right]^{\mathrm{C}}$ thin films. From Fig. 10, it is observed, the calculated values of the real part $\varepsilon_{1}(\lambda)$ are higher than of the imaginary part $\varepsilon_{2}(\lambda)$ for both $[\mathrm{BTB}]^{\mathrm{TF}}$ and $\left[\mathrm{ZrO}_{2}+\mathrm{BTB}\right]^{\mathrm{C}}$ thin films. Also, $\varepsilon_{1}(\lambda)$ and $\varepsilon_{2}(\lambda)$ parts for $[\mathrm{BTB}]^{\mathrm{TF}}$ films spectral profile have the same trend of behavior. During the whole spectra ranged from $1.5 \mathrm{eV} \leq \mathrm{hv} \leq$ $5.5 \mathrm{eV},[\mathrm{BTB}]^{\mathrm{TF}}$ pattern is characterized by a main broad peak in the photon energy range $2.5 \mathrm{eV} \leq$ $h v \leq 3.5 \mathrm{eV}$. Since the maximum value of both $\varepsilon_{1}(\lambda)$ and $\varepsilon_{2}(\lambda)$ has been obtained correspond to $h v=$ $2.94 \mathrm{eV}$. But, in the case of $\left[\mathrm{ZrO}_{2}+\mathrm{BTB}\right]^{\mathrm{C}}$ nanocomposite thin film, the spectral behavior is characterized by three broad peaks corresponding to photon energies of $2.94 \mathrm{eV}, 3.75 \mathrm{eV}$, and $4.41 \mathrm{eV}$. At the same time, $\varepsilon_{1}(\lambda)$ maximum spectral peak of $\left[\mathrm{ZrO}_{2}+\mathrm{BTB}\right]^{\mathrm{C}}$ nanocomposite film has severed into two peaks corresponding to $2.71 \mathrm{eV}$ and $3.17 \mathrm{eV}$ respectively. The creation of the three peaks in a photon energy range $1.5 \mathrm{eV}$ to $5.5 \mathrm{eV}$ in $\varepsilon_{1}(\lambda)$ and $\varepsilon_{2}(\lambda)$ patterns could be attributed due to $\pi \rightarrow \pi^{*}$ electronic transition. Also, the

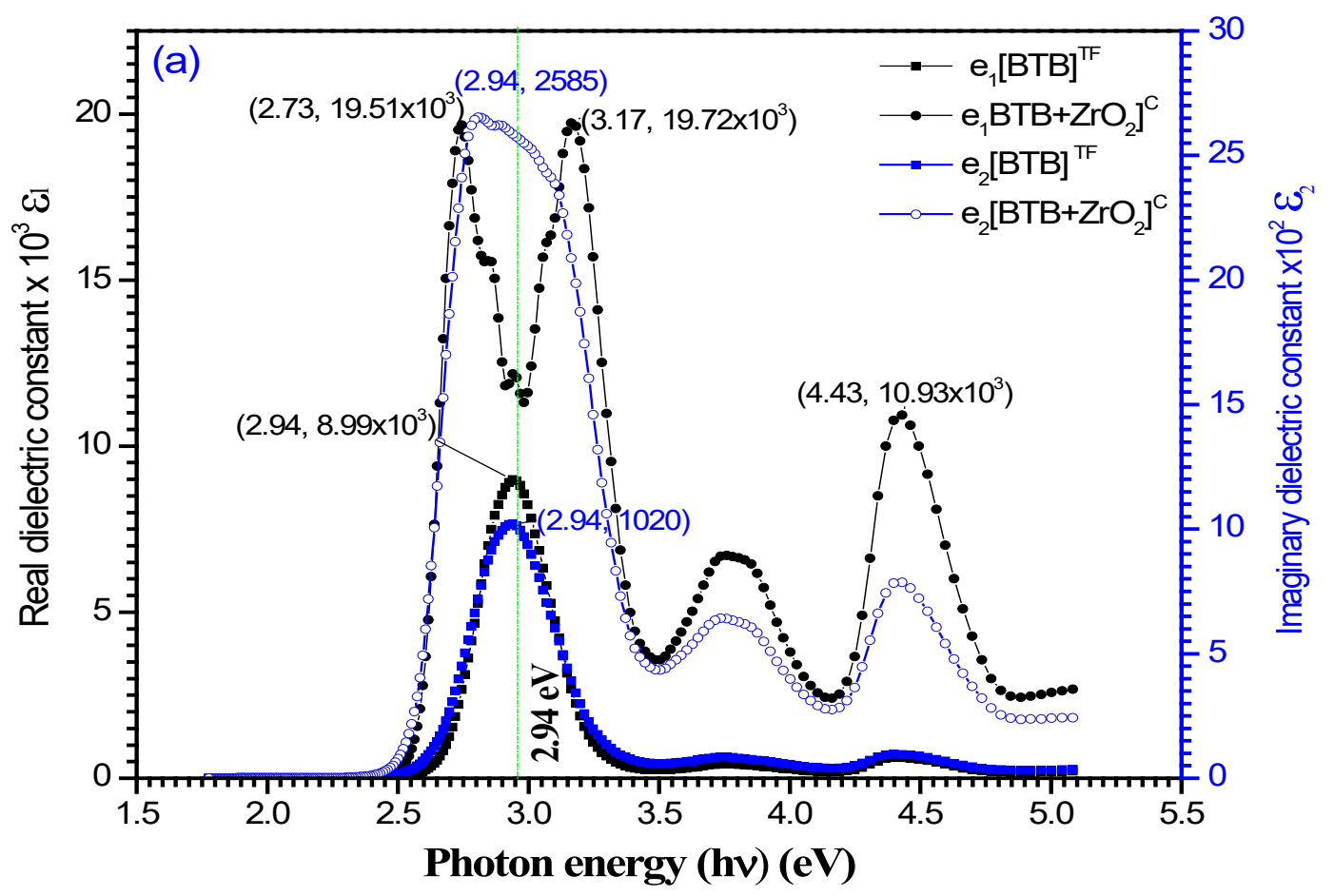




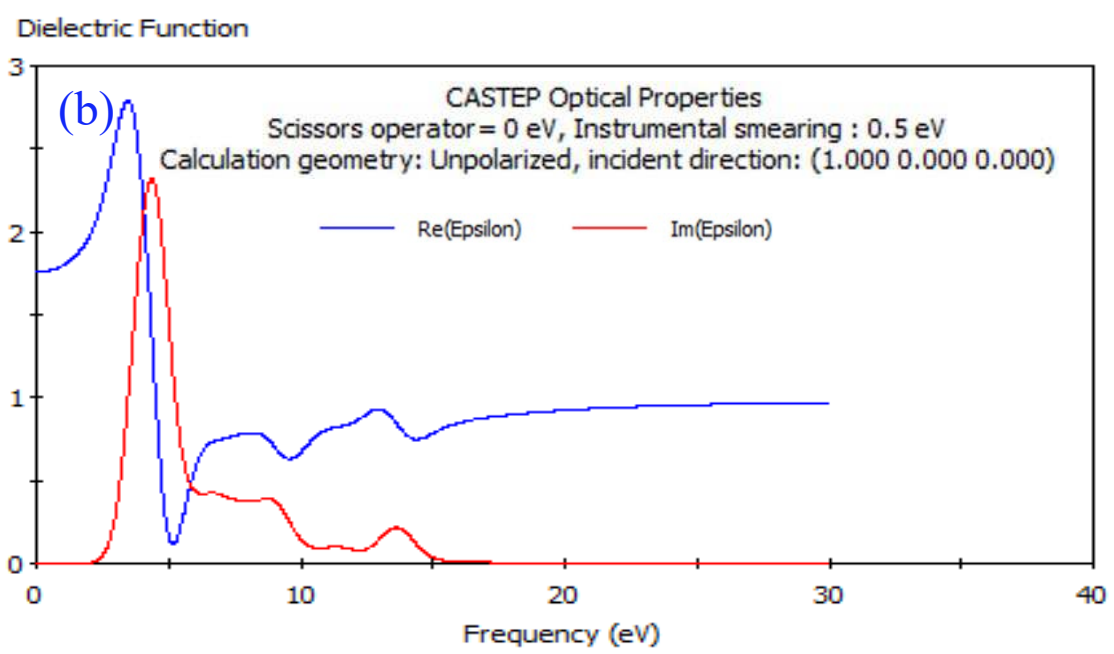

Dielectric Function

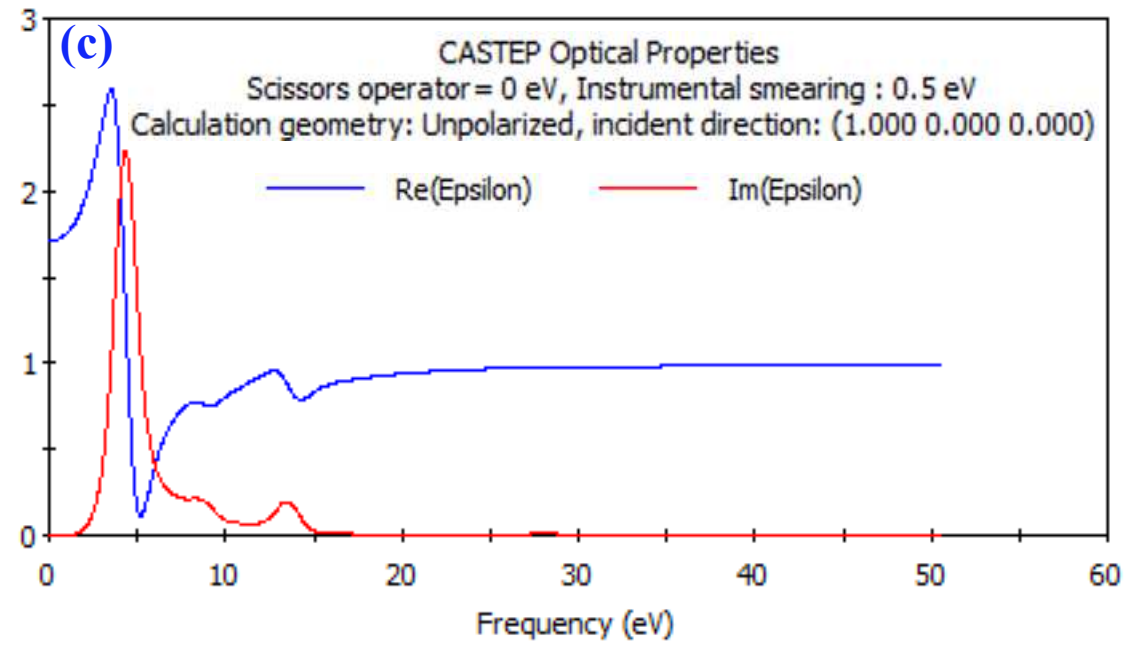

Fig. 10 a) Experimental $\varepsilon_{1}(\lambda)$ and $\varepsilon_{2}(\lambda)$ via h $v$ for [BTB]TF and $\left[\mathrm{ZrO}_{2}+\mathrm{BTB}\right]^{\mathrm{C}}$, b) $\varepsilon_{1}$ and $\varepsilon_{2}$ simulation optical prop erties for $[\mathrm{BTB}]$ and $\left[\mathrm{ZrO}_{2}+\mathrm{BTB}\right]^{\mathrm{C}}$ by using CASTEP method in DFT

Interactions between photons and electrons in both $[\mathrm{BTB}]^{\mathrm{TF}}$ and $[\mathrm{ZrO} 2+\mathrm{BTB}]^{\mathrm{C}}$ leads to the variations of both $\varepsilon_{1}(\lambda)$ and $\varepsilon_{2}(\lambda)$ profiles. Additionally, the ratio $\frac{\varepsilon_{1}(\lambda)}{\varepsilon_{2}(\lambda)}$ are 10 times, for both [BTB] ${ }^{\mathrm{TF}}$ and $\left[\mathrm{ZrO}_{2}+\mathrm{BTB}\right]^{\mathrm{C}}$ films, which means that $\varepsilon_{1}(\lambda)$ is predominated. By using the CASTEP method in DFT, the maximum values of $\varepsilon_{1}(\lambda)$ and $\varepsilon_{2}(\lambda)$ are related to frequency $\cong 3.12 \mathrm{eV}$ and $4.89 \mathrm{eV}$ for $[\mathrm{BTB}\}^{\mathrm{TF}}$, respectively, as shown in Fig. 10b. And, the maximum values of $\varepsilon_{1}(\lambda)$ and $\varepsilon_{2}(\lambda)$ are related to frequency $\cong 3.75 \mathrm{eV}$ and $5.00 \mathrm{eV}$ for $\left[\mathrm{ZrO}_{2}+\mathrm{BTB}\right\}^{\mathrm{C}}$, respectively, as shown in Fig. 10c.

Finally, it is remarked that, the outcomes from the experimental technique and CASTEP calculations for the maximum peaks of $\varepsilon_{1}(\lambda)$ and $\varepsilon_{2}(\lambda)$ for $[\mathrm{BTB}]^{\mathrm{TF}}$ and $\left[\mathrm{ZrO}_{2}+\mathrm{BTB}\right\}^{\mathrm{C}}$ films is located at range $h v \cong 2.71-3.17 \mathrm{eV}$ ( precisely at $h v=2.94 \mathrm{eV}$ ). Since, $\varepsilon_{1}(\lambda)$ is predominated case, the actual comparison must be between the $\varepsilon_{1}(\lambda)$ values in experimental method and $\varepsilon_{1}(\lambda)$ calculated from the CASTEP method which overall is in the range of $h v \cong 3.75-4.5 \mathrm{eV}$. The electrical conductivity of any semiconducting materials depends initially on the state of the delocalization of the electrons. The movement of charge carriers such as ions and electrons in the crystal lattice, and induced by the incident 
electromagnetic waves, stimulate also an increase of conductivity. While the optical response of the material is determined by the complex optical conductivity $\sigma^{*}(\lambda)$ established by the following expression [79]:

$$
\sigma^{*}(\omega)=\sigma_{1}(\omega)+i \sigma_{2}(\omega)
$$

Where $\left(\sigma_{1}(\lambda)\right)$ is the real part and $\left(\sigma_{2}(\lambda)\right)$ is the imaginary part of the optical conductivity. The values of real and imaginary parts are given by the relations $[80,81]$ :

$$
\begin{gathered}
\sigma_{1}(\omega)=\omega \varepsilon_{2} \varepsilon_{0}=2 \omega \varepsilon_{0} n k \\
\sigma_{2}(\omega)=\omega \varepsilon_{1} \varepsilon_{0}=\omega \varepsilon_{0}\left(n^{2}-k^{2}\right)
\end{gathered}
$$

Where $\omega$ is the angular frequency, $\varepsilon_{0}$ the permittivity of free space (free space dielectric constant). The dependence of the real and imaginary parts of the optical conductivity on the incident photon energy of our samples is shown in Fig.11 (a-c).

Fig. 11 shows the dependence of optical conductivity of $[\mathrm{BTB}]^{\mathrm{TF}}$ and $\left[\mathrm{ZrO}_{2}+\mathrm{BTB}\right]^{\mathrm{C}}$ thin films $(150 \mathrm{~nm}$ thickness) with photon energy ranged from $1.5 \mathrm{eV} \leq h v \leq 5.5 \mathrm{eV}$. Where, Fig. 11a displays the experimental behavior of the optical conductivity with $h v$, while Figs.11 (b and c) demonstrates the simulation using CASTEP in the DFT method of $[\mathrm{BTB}]^{\mathrm{TF}}$ and $\left[\mathrm{ZrO}_{2}+\mathrm{BTB}\right]^{\mathrm{C}}$, respectively. From Fig. 11a, it is observed that, the spectral behavior of $\sigma_{1}$ and $\sigma_{2}$ have the same pattern as that $\varepsilon_{2}(\lambda)$ and $\varepsilon_{1}(\lambda)$, respectively. Since Optical conductivity activity may be attributed due to the excitation of electrons.

The real conductivity $\left(\sigma_{1}\right)$ for $[\mathrm{BTB}]^{\mathrm{TF}}$ has a unique characterized broad peak of $\left(4 \times 10^{6} \Omega^{-1} \mathrm{~m}^{-1}\right.$ at $\mathrm{h} v=2.94 \mathrm{eV})$, while $\left[\mathrm{ZrO}_{2}+\mathrm{BTB}\right]^{\mathrm{C}}$ thin film has three distinct peaks at $\left(72.75 \times 10^{5}, 8.39 \times 10^{6}\right.$, and $\left.65.14 \times 10^{5} \Omega^{-1} \mathrm{~m}^{-1}\right)$ corresponding to photon energies $(2.94,3.75$, and $4.41 \mathrm{eV})$, respectively. On the other hand, $\sigma_{2}$ imaginary optical conductivity, for $[\mathrm{BTB}]^{\mathrm{TF}}$ still has a single peak at the same photon energy as $\sigma_{1}$. But, in the case of $\left[\mathrm{ZrO}_{2}+\mathrm{BTB}\right]^{\mathrm{C}}$ a splitting in the $1^{\text {st }}$ distinguished peak into two of energies 2.71 and $3.18 \mathrm{eV}$, respectively. Also, an increase in the maximum values of $\sigma_{2}$ of both $2^{\text {nd }}$ and $3^{\text {rd }}$ peaks. Enhances of the optical conductivity of $\left[\mathrm{ZrO}_{2}+\mathrm{BTB}\right]^{\mathrm{C}}$ film may be attributed to the high absorption coefficient associated with charge ordering effect and refractive index. Where the optical conductivity and the absorption coefficient are related by the following relation [82-83]: $\sigma=\alpha n c / 4 \pi$, where $\mathrm{c}$ is the light speed, and $\alpha$ is the absorption coefficient. This relation tells us that the optical conductivity is linearly dependent on the refractive index and absorption coefficient.

Finally, Fig. 11 (b-c) show the spectral dependence of optical conductivity $\sigma(\omega)$ versus photon energy $(h v)$ for $[\mathrm{BTB}]^{\mathrm{TF}}$ and $\left[\mathrm{ZrO}_{2}+\mathrm{BTB}\right]^{\mathrm{C}}$ as-single by using CASTEP in the DFT simulation method. The simulation and experimental behavior of optical conductivity $\sigma(\omega)$ are similar in behavior with different intensity of peaks and the photon energies $(h v)$ values. The simulation curves for $[\mathrm{BTB}]^{\mathrm{TF}}$ and 
$\left[\mathrm{ZrO}_{2}+\mathrm{BTB}\right]^{\mathrm{C}}$ compounds indicate strong conformity compared with the experimental curve. Both $\sigma_{1}$ and $\sigma_{2}$ of $[\mathrm{BTB}]^{\mathrm{TF}}$ and $\left[\mathrm{ZrO}_{2}+\mathrm{BTB}\right]^{\mathrm{C}}$ have a directly proportional with increasing $h v$ up to $4.50 \mathrm{eV}$.

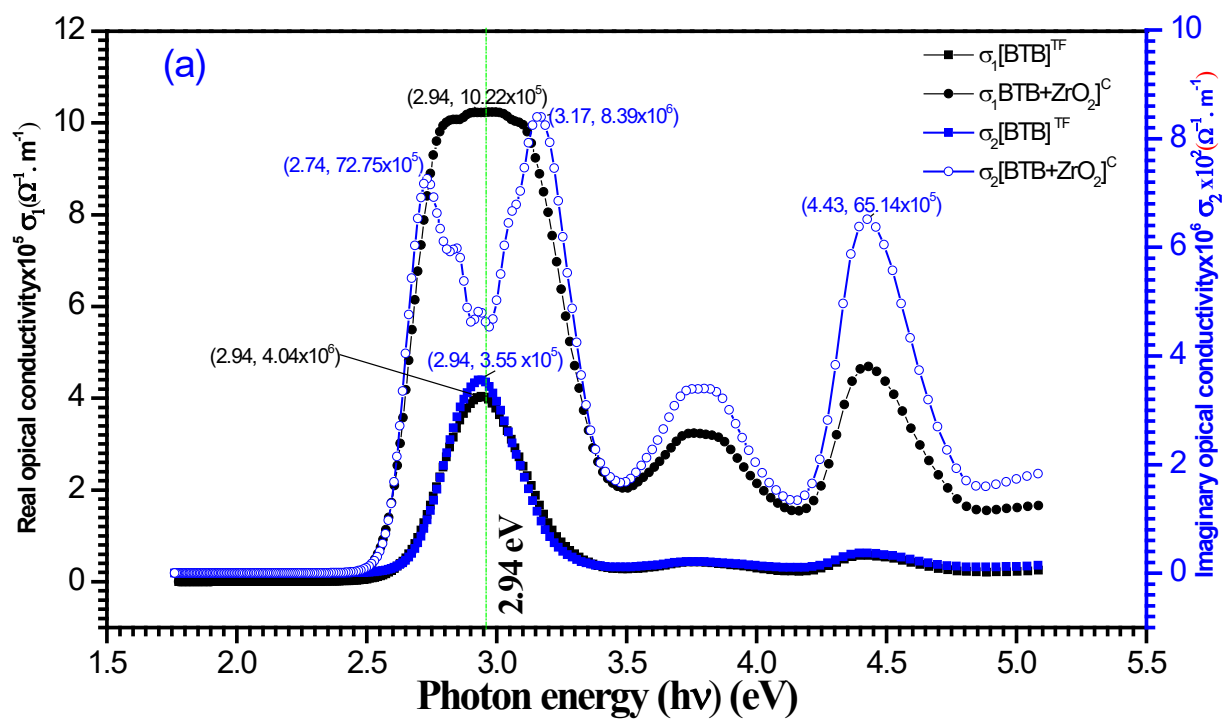

Conductivity $(1 / \mathrm{fs})$

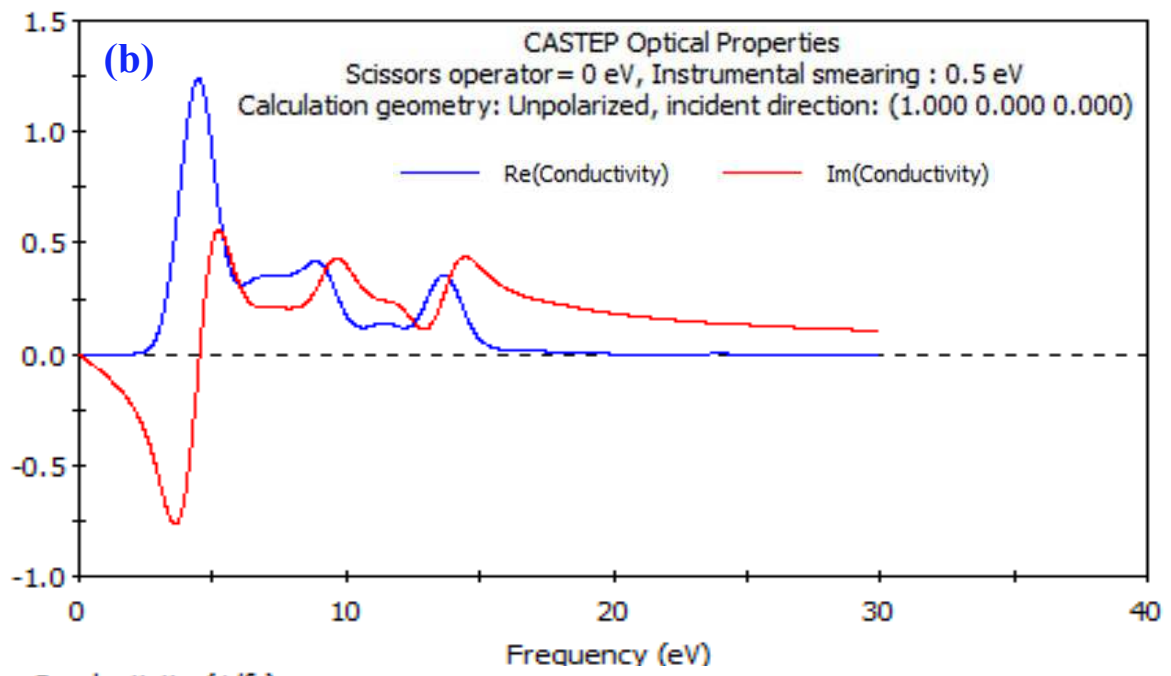

Conductivity (1/fs)

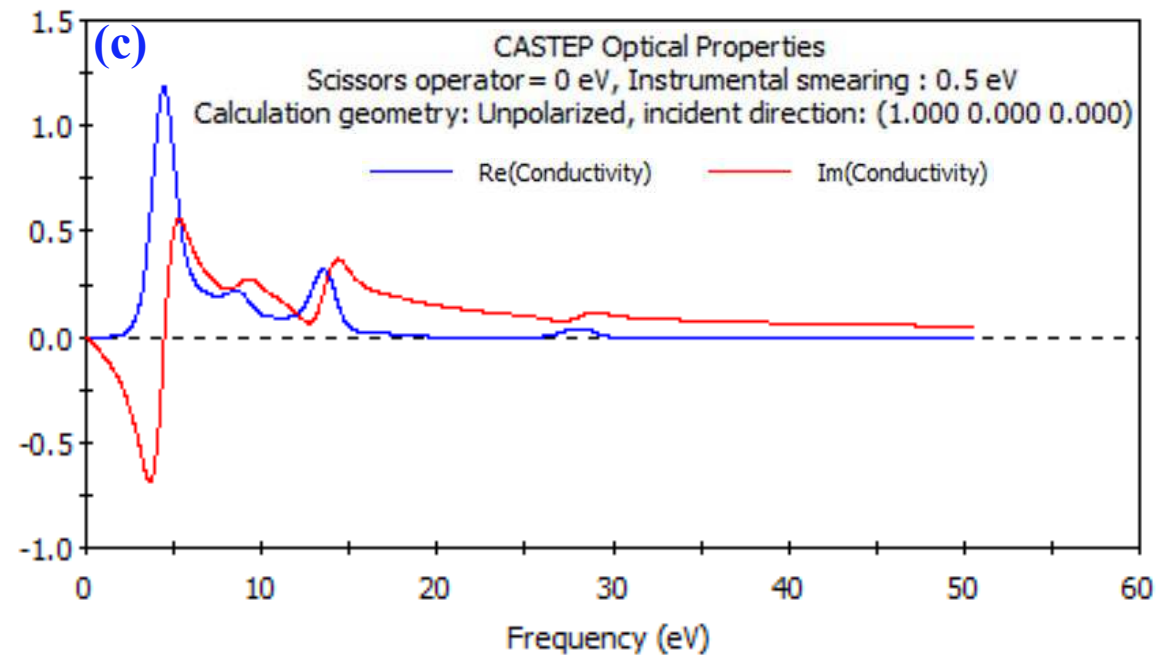

Fig. 11 a) Experimental $\sigma_{1}$ and $\sigma_{2}$ via hv for $[\mathrm{BTB}]^{\mathrm{TF}}$ and $\left[\mathrm{ZrO}_{2}+\mathrm{BTB}\right]^{\mathrm{C}}$, b-c) $\sigma_{1}$ and $\sigma_{2}$ simulation optical properties for $[\mathrm{BTB}]$ and $\left[\mathrm{ZrO}_{2}+\mathrm{BTB}\right]^{\mathrm{C}}$ by using CASTEP method in DFT, respectively. 


\section{Conclusion}

In this work, novel bromothymol blue dyes $[\mathrm{BTB}]^{\mathrm{TF}}$ and $\left[\mathrm{ZrO}_{2}+\mathrm{BTB}\right]^{\mathrm{C}}$ as-deposited thin films are fabricated by using the Sol-gel spin coating technique. The molecular structural characteristics of $[\mathrm{BTB}]^{\mathrm{TF}}$ and $\left[\mathrm{ZrO}_{2}+\mathrm{BTB}\right]^{\mathrm{C}}$ compounds are determined using FTIR, MEP, ED techniques. The crystalline structure and morphology of $[\mathrm{BTB}]^{\mathrm{TF}}$ and $\left[\mathrm{ZrO}_{2}+\mathrm{BTB}\right]^{\mathrm{C}}$ films are investigated by XRD and SEM techniques. Since the nanofibers of $\left[\mathrm{ZrO}_{2}+\mathrm{BTB}\right],{ }^{\mathrm{C}}$ film is attributed to the presence of $\left[\mathrm{ZrO}_{2}\right]^{\mathrm{NPs}}$. the $\mathrm{XRD}$ reveals that the same crystal structure was remarked for $[\mathrm{BTB}]^{\mathrm{TF}}$ and $\left[\mathrm{ZrO}_{2}+\mathrm{BTB}\right]^{\mathrm{C}}$ (Orthorhombic) with space group (P6 1$)$. Optical dispersion parameters, dielectric and optical conductivity properties of $\left[4-[\mathrm{BTB}]^{\mathrm{TF}}\right.$ and $\left[\mathrm{ZrO}_{2}+\mathrm{BTB}\right]^{\mathrm{C}}$ as-deposited thin films are calculated experimentally and by simulation by using CASTEP in the DFT method. There is a good agreement between optical energy gap values determined by Tauc's equation calculations and that obtained by DFT $\left(\mathrm{DMol}^{3}\right)$ computations. Directallowed electronic transition is the predominated case.

\section{References}

[1] Q. Zhao, X. Gan, Q. Lei, W. Li, K. Zhou, Enhanced the strength and ductility of the partially unzipped carbon nanotubes reinforced $\mathrm{CuCr}$ matrix composites via optimization of the interface structure, Composite Interfaces, 2019, https://doi.org/10.1080/09276440.2019.1707026.

[2] A. Daham, A. Zegaoui, H.A. Ghouti, M. Derradji, W.-a. Cai, J. Wang, W.-b. Liu, J.-y. Wang, Z. Moussa, Structural, morphological and mechanical properties of hyperbranched polymers coated carbon fibers reinforced DCBA/BA-a composites, Composite Interfaces, 2019, https://doi.org/10.1080/09276440.2019.1708672.

[3] De Meyer, Thierry, Substituent effects on absorption spectra of $\mathrm{pH}$ indicators: An experimental and computational study of sulfonphthaleine dyes, Dyes and Pigments. 102 (2014) 241-250.

[4] G.D. Christian, Analytical Chemistry, sixth ed. Wiley \& Sons, Hoboken, N.J.,2004.

[5] J.B. Puschett, B.S. Rao, B.M. Karandikar, K. Matyjaszewski, Indicator characteristics of bromothymol blue derivatives, Talanta 38 (1991) 335-338.

[6] I. M. El Nahhal, S. M. Zourab, F.S. Kodeh, A. Qudaih, Thin film optical BTB pH sensors using solgel method in presence of surfactants, International Nano Letters 2 (2012)1-9.

[7] M.S. Zoromba, A. Al-Hossainy, Doped poly (o-phenylenediamine-co-p-toluidine) fibers for polymer solar cells applications, Solar Energy, 195 (2020) 194-209.

[8] R. Buntem, A. Intasiri, W. Lueangchaichaweng, Facile synthesis of silica monolith doped with mesotetra(p-carboxyphenyl)- porphyrin as a novel metal ion sensor, J Colloid Interface Sci 347 (2010) 814.

[9] S.A. Mahmoud, A.A. Al-Dumiri, A. Al-Hossainy, Combined experimental and DFT-TDDFT computational studies of doped [PoDA $+\mathrm{PpT} / \mathrm{ZrO} 2] \mathrm{C}$ nanofiber composites and its applications, Vacuum, (2020) 109777. https://doi.org/10.1016/j.vacuum.2020.109777.

[10] A. Walcarius, M.M. Collinson, Analytical chemistry with silica sol-gels: traditional routes to new materials for chemical analysis, Annu. Rev. Anal. Chem. 2(2009) 121-143.

[11] J. Tan, H.F. Wang, X.P. Yan, Discrimination of saccharides with a fluorescent molecular imprinting sensor array based on phenylboronic acid functionalized mesoporous silica, Anal. Chem. 81(2009) 5273-5280.

[12] A.F. Al-Hossainy, A.E. Mohamed, F.S. Hassan, M.A. Allah, Determination of cadmium and lead in perch fish samples by differential pulse anodic stripping voltammetry and furnace atomic absorption spectrometry, Arabian Journal of Chemistry, 10 (2017) S347-S354. 
[13] T. N. Vieirade Souza, S. M. Leãode Carvalho, M. G. AdeodatoVieira, M. G. Carlosda Silva, D. do S. Barros Brasil, Adsorption of basic dyes onto activated carbon: Experimental and theoretical investigation of chemical reactivity of basic dyes using DFT-based descriptors, Applied Surface Science 448 (2018) 662-670.

[14] T. Le Bahers , T. Pauporté , G. Scalmani , C. Adamo, I. Ciofini , A TD-DFT investigation of ground and excited state properties in indoline dyes used for dye-sensitized solar cells, Phys. Chem. Chem. Phys. 11 (2009) 11276-11284.

[15] M. Mojbafan, F. Zanjanchi, M. Taherkhani, The influence of physical factors on the halochromic behavior of the $\mathrm{pH}$-sensitive sulfonphthaleine dyes: a DFT study, Chemical Papers 74(2020) 43554363.

[16] T. Yamaguchi, Application of $\mathrm{ZrO}_{2}$ as a catalyst and a catalyst support, Catalysis Today 20 (1994) 199-217.

[17] F. Monte, W. Larsen, J.D. Mackenzie, Stabilization of tetragonal $\mathrm{ZrO}_{2}$ in $\mathrm{ZrO}_{2}-\mathrm{SiO}_{2}$ binary oxides, Journal of the American Ceramic Society 83 (2000) 628-634.

[18] N. Almutlaq, A. Al-Hossainy, Novel synthesis, structure characterization, DFT and investigation of the optical properties of diphenylphosphine compound/zinc oxide [DPPB $+\mathrm{ZnO}$ ] C nanocomposite thin film, Composite Interfaces, (2020) https://doi.org/10.1080/09276440.2020.1817682.

[19] T. J. Brunner, P. Wick, P. Manser, P. Spohn, R.N. Grass, L.K. Limbach, A. Bruinink, W.J. Stark, In vitro cytotoxicity of oxide nanoparticles: comparison to asbestos, silica, and the effect of particle solubility, Environmental science \& technology 40 (2006) 4374-4381.

[20] M.Q. Al-Fahdawi, A. Rasedee, M.S. Al-Qubaisi, F.H. Alhassan, R. Rosli, M.E. El Zowalaty, S.-E. Naadja, T.J. Webster, Y.H. Taufiq-Yap, cytotoxicity and physicochemical characterization of ironmanganese-doped sulfated zirconia nanoparticles, International journal of nanomedicine 10 (2015) $5739-5750$.

[21] G. Garnweitner, L.M. Goldenberg, O.V. Sakhno, M. Antonietti, M. Niederberger, J. Stumpe, LargeScale Synthesis of Organophilic Zirconia Nanoparticles and their Application in Organic-Inorganic Nanocomposites for Efficient Volume Holography, Small, 3 (2007) 1626-1632.

[22] X. Xu, X. Wang, Fine tuning of the sizes and phases of $\mathrm{ZrO}_{2}$ nanocrystals, Nano Research, 2 (2009) 891-902.

[23] M. Taguchi, S. Takami, T. Adschiri, T. Nakane, K. Sato, T. Naka, Simple and rapid synthesis of $\mathrm{ZrO} 2$ nanoparticles from $\mathrm{Zr}(\mathrm{OEt})_{4}$ and $\mathrm{Zr}(\mathrm{OH})_{4}$ using a hydrothermal method, Cryst. Eng. Comm. 14 (2012) 2117-2123.

[24] T.A. Cheema, G. Garnweitner, Phase-controlled synthesis of $\mathrm{ZrO} 2$ nanoparticles for highly transparent dielectric thin films, Cryst. Eng. Comm. 16 (2014) 3366-3375.

[25] C. Friderichs, N. Zotov, W. Mader, Synthesis of monodisperse SrTi1-xZrxO3 nano cubes in oleate by a two- phase solvothermal method, European Journal of Inorganic Chemistry 2015 (2015) 288295.

[26] V.G. Deshmane, Y.G. Adewuyi, Synthesis of thermally stable, high surface area, nano crystalline mesoporous tetragonal zirconium dioxide $\left(\mathrm{ZrO}_{2}\right)$ : effects of different process parameters, Microporous and mesoporous materials 148 (2012) 88-100.

[27] V. Rebuttini, A. Pucci, P. Arosio, X. Bai, E. Locatelli, N. Pinna, A. Lascialfari, M.C. Franchini, Zirconia-doped nanoparticles: organic coating, polymeric entrapment and application as dualimaging agents, Journal of Materials Chemistry B 1 (2013) 919-923.

[28]M.S. Zoromba, M. Abdel-Aziz, M. Bassyouni, A. Attar, A. Al-Hossainy, Synthesis and characterization of Poly (ortho-aminophenol-co-para-toluidine) and its application as semiconductor thin film, Journal of Molecular Structure, (2020) 129131. https://doi.org/10.1016/j.molstruc.2020.129131

[29] C. Liu, T.J. Hajagos, D. Chen, Y. Chen, D. Kishpaugh, Q. Pei, Efficient one-pot synthesis of colloidal zirconium oxide nanoparticles for high-refractive-index nanocomposites, ACS Applied materials \& interfaces 8 (2016) 4795-4802.

[30] V. Bansal, D. Rautaray, A. Ahmad, M. Sastry, Biosynthesis of zirconia nanoparticles using the fungus Fusarium oxysporum, Journal of Materials Chemistry 14 (2004) 3303-3305. 
[31] W. Cao, J. Kang, G. Fan, L. Yang, F. Li, Fabrication of porous $\mathrm{ZrO}_{2}$ nanostructures with controlled crystalline phases and structures via a facile and cost-effective hydrothermal approach, Industrial \& Engineering Chemistry Research 54 (2015) 12795-12804.

[32] Y. Si, Z. Guo, Super hydrophobic nano coatings: from materials to fabrications and to applications, Nanoscale 7 (2015) 5922-5946.

[33] M.A. Sliem, D.A. Schmidt, A.l. Bétard, S.B. Kalidindi, S. Gross, M. Havenith, A. Devi, R.A. Fischer, Surfactant-induced non hydrolytic synthesis of phase-pure $\mathrm{ZrO}_{2}$ nanoparticles from metalorganic and Oxo cluster precursors, Chemistry of Materials 24 (2012) 4274-4282.

[34] R. Srinivasan, R.J. De Angelis, G. Ice, B.H. Davis, Identification of tetragonal and cubic structures of zirconia using synchrotron X-radiation source, Journal of materials research 6 (1991) 1287-1292.

[35] A. Al-Hossainy, M. Bassyouni, M.S. Zoromba, Elucidation of electrical and optical parameters of poly (o-anthranilic acid)-poly (o-amino phenol)/copper oxide nanocomposites thin films, Journal of Inorganic and Organometallic Polymers and Materials, 28 (2018) 2572-2583.

[36] N. Zhao, D. Pan, W. Nie, X. Ji, Two-phase synthesis of shape-controlled colloidal zirconia nanocrystals and their characterization, Journal of the American Chemical Society 128 (2006) 1011810124.

[37] A. Amoozadeh, S. Rahmani, M. Bitaraf, F.B. Abadi, E. Tabrizian, Nano-zirconia as an excellent nano support for immobilization of sulfonic acid: a new, efficient and highly recyclable heterogeneous solid acid nano catalyst for multicomponent reactions, New Journal of Chemistry 40 (2016) 770-780.

[38] A. Jain, S. Ranjan, N. Dasgupta, C. Ramalingam, Nanomaterials in Food and Agriculture: An overview on their safety concerns and regulatory issues, Critical reviews in food science and nutrition (2016) 1-86.

[39] A. Al-Hossainy, M.S. Zoromba, M. Abdel-Aziz, M. Bassyouni, A. Attar, M. Zwawi, A. AbdElmageed, H. Maddah, A.B. Slimane, Fabrication of heterojunction diode using doped-poly (orthoaminophenol) for solar cells applications, Physica B: Condensed Matter, 566 (2019) 6-16.

[40] O. Dimitrov, I. Stambolova, S. Vassilev, K. Lazarova, T. Babeva, R. Mladenova, Surface and morphological features of $\mathrm{ZrO}_{2}$ sol-gel coatings obtained by polymer modified solution, Mater. Proc. 2 (2020) doi:10.3390/CIWC2020-06810.

[41] I.M. Awad, F.S. Hassan, A.E. Mohamed, A.F. Al-Hossainy, Diphosphine compounds: part I. novel biologically active $1,1^{\prime}$ bis-AND/OR 1, 2-cis-(diphenylphosphino-) ethene and their complexes [M (CO) n $\{\mathrm{Ph} 2 \mathrm{P}(\mathrm{CHn}) \mathrm{nPPh} 2\}] \&[\mathrm{Cu}(\mathrm{Cl}) 2\{\mathrm{Ph} 2 \mathrm{P}(\mathrm{CHn}) \mathrm{nPPh} 2\}],(\mathrm{M}=\mathrm{W}, \mathrm{Mo}, \mathrm{Crn}=1,2 \ldots \mathrm{n})$, Phosphorus, Sulfur, and Silicon, 179 (2004) 1251-1266.

[42] A. M. Shaker, R. M. El-Khatib, L. A. E. Nasser, Further mechanistic orientation for the oxidation reaction between alkaline permanganate and poly galacturonate methyl ester. Novel spectrophotometric tracer of intrahypomanganate (V) - Intermediate, Carbohyd. Poly. 78 (2009) 710716.

[43] I.M. Awad, F.S. Hassan, A.E. Mohamed, A.F. Al-Hossainy, Diphosphine compounds: part I. novel biologically active $1,1^{\prime}$ bis-AND/OR 1, 2-cis-(diphenylphosphino-) ethene and their complexes [M $(\mathrm{CO}) \mathrm{n}\{\mathrm{Ph} 2 \mathrm{P}(\mathrm{CHn}) \mathrm{nPPh} 2\}] \&[\mathrm{Cu}(\mathrm{Cl}) 2\{\mathrm{Ph} 2 \mathrm{P}(\mathrm{CHn}) \mathrm{nPPh} 2\}],(\mathrm{M}=\mathrm{W}, \mathrm{Mo}, \mathrm{Crn}=1,2 \ldots \mathrm{n})$, Phosphorus, Sulfur, and Silicon, 179 (2004) 1251-1266.

[44] M. S. Manhas, F. Mohammed, Z. Khan, A kinetic study of oxidation of b-cyclodextrin by permanganate in aqueous media, Coll. Surf. 295 (2007) 165-171.

[45] A. Al-Hossainy, M.S. Zoromba, O. El-Gammal, F.I. El-Dossoki, Density functional theory for investigation of optical and spectroscopic properties of zinc-quinonoid complexes as semiconductor materials, Structural Chemistry, 30 (2019) 1365-1380.

[46] C. Rottman, G. Grader, Y.D. Hazan, S. Melchior, D. Avinir, Surfactant-induced modification of dopants reactivity in sol-gel matrixes, J. Am. Chem. Soc. 121(1999) 8533-8543.

[47] M. Abdel-Aziz, A.F. Al-Hossainy, A. Ibrahim, S. Abd El-Maksoud, M.S. Zoromba, M. Bassyouni, S. Abdel-Hamid, A. Abd-Elmageed, I. Elsayed, O. Alqahtani, Synthesis, characterization and optical properties of multi-walled carbon nanotubes/aniline-o-anthranilic acid copolymer nanocomposite thin films, Journal of Materials Science: Materials in Electronics, 29 (2018) 16702-16714. 
[48] I.M. El-Nahhal, S. M. Zourab, F. S. Kodeh, F. H. Abdelsalam, Sol-gel encapsulation of bromothymol blue $\mathrm{pH}$ indicator in presence of Gemini 12-2-12 surfactant, J. Sol-Gel. Sci. Technol. 71(2014)16-23.

[49] A.F. Al-Hossainy, A. Ibrahim, The effects of annealing temperature on the structural properties and optical constants of a novel DPEA-MR-Zn organic crystalline semiconductor nanostructure thin films, Optical Materials, 73 (2017) 138-153.

[50] S.M. Ibrahim, A. Bourezgui, A. Abd-Elmageed, I. Kacem, A.F. Al-Hossainy, Structural and optical characterization of novel $[\mathrm{ZnKCMC}]{ }^{\mathrm{TF}}$ for optoelectronic device applications, Journal of Materials Science: Materials in Electronics, 31(2020) 8690-8704.

[51] N. Jäger, M. Meindlhumer, S. Spor, H. Hruby, J. Julin, A. Stark, F. Nahif, J. Keckes, C. Mitterer, R. Daniel, Microstructural evolution and thermal stability of $\mathrm{AlCr}(\mathrm{Si}) \mathrm{N}$ hard coatings revealed by insitu high-temperature high-energy grazing incidence transmission X-ray diffraction, Acta Materialia, 186 (2020) 545-554.

[52] A.F. Al-Hossainy, M.R. Eid, M.S. Zoromba, Structural, DFT, optical dispersion characteristics of novel [DPPA-Zn-MR $\left.(\mathrm{Cl})\left(\mathrm{H}_{2} \mathrm{O}\right)\right]$ nanostructured thin films, Materials Chemistry and Physics 232 (2019) 180-192.

[53] D. C. Arnold, K. S. Knight, F. D. Morrison, P. Lightfoot, Ferroelectric-paraelectric transition in BiFeO3: Crystal structure of the orthorhombic $\beta$ phase, Phys. Rev. Lett. 102 (2009) 027602 .

[54] M. Abdel-Aziz, M.S. Zoromba, M. Bassyouni, M. Zwawi, A. Alshehri, A. Al-Hossainy, Synthesis and characterization of Co-Al mixed oxide nanoparticles via thermal decomposition route of layered double hydroxide, Journal of Molecular Structure, DOI (2020) 127679.

[55] A. Al-Hossainy, H.K. Thabet, M.S. Zoromba, A. Ibrahim, Facile synthesis and fabrication of a poly (ortho-anthranilic acid) emeraldine salt thin film for solar cell applications, New Journal of Chemistry 42 (2018) 10386-10395.

[56] S. Gražulis, D. Chateigner, R. T. Downs, A. F. T. Yokochi, M. Quirós, L. Lutterotti, E. Manakova, J. Butkus, P. Moeck, A. Le Bail, Crystallography Open Database - an open-access collection of crystal structures, J. Appl. Cryst. 42 (2009)726-729.

[57] J. Plášil, K. Fejfarová, K. S. Wallwork, M. Dušek, R.Škoda, J. Sejkora, J.Čejka, F. Veselovský, J. Hloušek, N. Meisser, J. Brugger, Crystal structure of pseudojohannite, with a revised formula, $\mathrm{Cu} 3(\mathrm{OH}) 2[(\mathrm{UO} 2) 4 \mathrm{O} 4(\mathrm{SO} 4) 2](\mathrm{H} 2 \mathrm{O}) 12$, American Mineralogist 97 (2012) 1796-1803.

[58] M.Sh. Zoromba, M.H. Abdel-Aziz, M. Bassyouni, H. Bahaitham, A. Al-Hossainy, Poly (ophenylenediamine) thin film for organic solar cell applications. J. Solid State Electrochem. 22 (2018) 3673-3687.

[59] A.Ibrahim, A. Al-Hossainy, Thickness dependence of structural and optical properties of novel 2$((1$, 1-bis (diphenylphosphino)-2-phenylpropan-2-yl)-chromium tetracarbonyl-amino)-3phenylpropanoic acid copper (II)(DPP-Cr-Palan-Cu), nanocrystalline thin film. Synth. Met. 209 (2015) 389-398.

[60] A.F. Al-Hossainy, R.M. Abdelaal, W.N. El Sayed, Novel synthesis, structure characterization, DFT and investigation of the optical properties of cyanine dye/zinc oxide [4-CHMQI/ZnO] C nanocomposite thin film, Journal of Molecular Structure, 1224 (2020) 128989.

[61] A.M. El Sayed, G. Said, S. Taha, A. Ibrahim, F. Yakuphanoglu, Influence of copper incorporation on the structural and optical properties of $\mathrm{ZnO}$ nanostructured thin films, Superlattices and Microstructures 62(2013) 47-58.

[62] H. Yao, D. Qian, H. Zhang, Y. Qin, B. Xu, Y. Cui, R. Yu, F. Gao, J. Hou, Critical role of molecular electrostatic potential on charge generation in organic solar cells, Chinese Journal of Chemistry, 36 (2018) 491-494.

[63] H.K. Thabet, A. Al-Hossainy, M. Imran, Synthesis, characterization, and DFT modeling of novel organic compound thin films derived from 2-amino-4-(2-hydroxy-3-methoxyphenyl)-4H-thiazolo [3, 2-a][1, 3, 5] triazin-6 (7H)-one, Optical Materials, 105 (2020) 109915.

[64] A.F. Al-Hossainy, A. Ibrahim, The effects of annealing temperature on the structural properties and optical constants of a novel DPEA-MR-Zn organic crystalline semiconductor nanostructure thin films. Opt. Mater. 73 (2017)138-153. 
[65] A. F. Al-Hossainy, A. Ibrahim, M. Sh. Zoromba, Synthesis and characterization of mixed metal oxide nanoparticles derived from $\mathrm{Co}-\mathrm{Cr}$ layered double hydroxides and their thin films, Journal of Materials Science: Materials in Electronics, 30 (2019) 11627-11642.

[66] M.I. El-Nahhal, S.M. Zourab, F.S. Kodeh, A. Kodeh, Nanostructured copper oxide-cotton fibers: synthesis, characterization, and applications, Int. Nano. Lett. 2(2012) 16.

[67] C. Rottman, G. Grader, Y.D. Hazan, S. Melchior, D. Avinir, Surfactant-induced modification of dopants reactivity in sol-gel matrixes, J. Am. Chem. Soc. 121(1999) 8533-8543.

[68] J. Tauc, A. Menth, States in the gap. J. Non-Cryst. Solids 8 (1972) 569-585.

[69] E.T. Thostenson, C. Li, T.-W. Chou, Nanocomposites in context, Compos. Sci. Technol. 65 (2005) 491-516.

[70] V. Choudhary, A. Bhatt, D. Dash, N. Sharma, DFT calculations on molecular structures, HOMOLUMO study, reactivity descriptors and spectral analyses of newly synthesized diorganotin (IV) 2chloridophenylacetohydroxamate complexes, Journal of computational chemistry, 40 (2019) 23542363.

[71] M. S. Zoromba, M. Bassyouni, M. Abdel-Aziz, A. F. Al-Hossainy, N. Salah, A. Al-Ghamdi, M. R. Eid, Structure and photoluminescence characteristics of mixed nickel-chromium oxides nanostructures, Appl. Phys. A: Mater. Sci. Process. 125 (2019) 642.

[72] S. M. Ibrahim , A. Bourezgui, A.F. Al-Hossainy, Novel synthesis, DFT and investigation of the optical and electrical properties of carboxymethyl cellulose/thiobarbituric acid/copper oxide [CMC + TBA/CuO]C nanocomposite film, Journal of Polymer Research (2020) 27:264.

[73] K.T. Sørensen, C.B. Ingvorsen, L.H. Nielsen, A. Kristensen, Effects of water-absorption and thermal drift on a polymeric photonic crystal slab sensor, Optics Express 26 (2018) 5416-5422.

[74] A. F. Al-Hossainy, R. M. Abdelaal, W. N. El Sayed, Novel synthesis, structure characterization, DFT and investigation of the optical properties of cyanine dye/zinc oxide [4-CHMQI/ZnO]C nanocomposite thin film, Journal of Molecular Structure (2021) 128989.

[75] F. Tepehan, N. Ozer, A simple method for the determination of the optical constants, $n$ and $k$ of cadmium sulfide films from transmittance measurements, Sol. Energy Mater. Sol. Cells 30 (1993) 353.

[76] S.M. Ibrahim, A. Bourezgui, A. Abd-Elmageed, I. Kacem, A.F. Al-Hossainy, Structural and optical characterization of novel [ZnKCMC] TF for optoelectronic device applications, Journal of Materials Science: Materials in Electronics, DOI (2020) 1-15.

[77] A.S. Faidah, Estimation of the dispersion and absorption parameters of thermally evaporated magnesium phthalocyanine thin films, JKAU: Sci. 21 (2009) 185-196.

[78] A. Badr, A. El-Amin, A. Al-Hossainy, Synthesis and optical properties for crystals of a novel organic semiconductor [Ni (Cl) $2\{(\mathrm{Ph} 2 \mathrm{P}) 2 \mathrm{CHC}(\mathrm{R} 1 \mathrm{R} 2) \mathrm{NHNH} 2\}]$, The European Physical Journal BCondensed Matter and Complex Systems, 53 (2006) 439-448.

[79] S. Younis, M. Usman, A. ul Haq, N. Akram, M. Saeed, S. Raza, M. Siddiq, F. Bukhtawar, Solubilization of reactive dyes by mixed micellar system: Synergistic effect of nonionic surfactant on solubilizing power of cationic surfactant, Chemical Physics Letters 738 (2020) 136890.

[80] A. Badr, A. El-Amin, A. Al-Hossainy, Elucidation of charge transport and optical parameters in the newly 1CR-dppm organic crystalline semiconductors, The Journal of Physical Chemistry C, 112 (2008) 14188-14195.

[81] M. Dongol, M.M. El-Nahass, A. El-Denglawey, A.F. Elhady, A.A. Abuelwafa, Optical properties of nano 5, 10, 15, 20-tetraphenyl-21H, 23H-prophyrin nickel (II) thin films, Curr. Appl. Phys. 12 (2012) 1178-1184.

[82] A. Abd-Elmageed, S. Ibrahim, A. Bourezgui, A. Al-Hossainy, Synthesis, DFT studies, fabrication, and optical characterization of the $[\mathrm{ZnCMC}] \mathrm{TF}$ polymer (organic/inorganic) as an optoelectronic device, New Journal of Chemistry, DOI (2020).

[83] A.I. Arbab, On the optical conductivity, Optik-International Journal for Light and Electron Optics194(2019), 163067. 
Figures

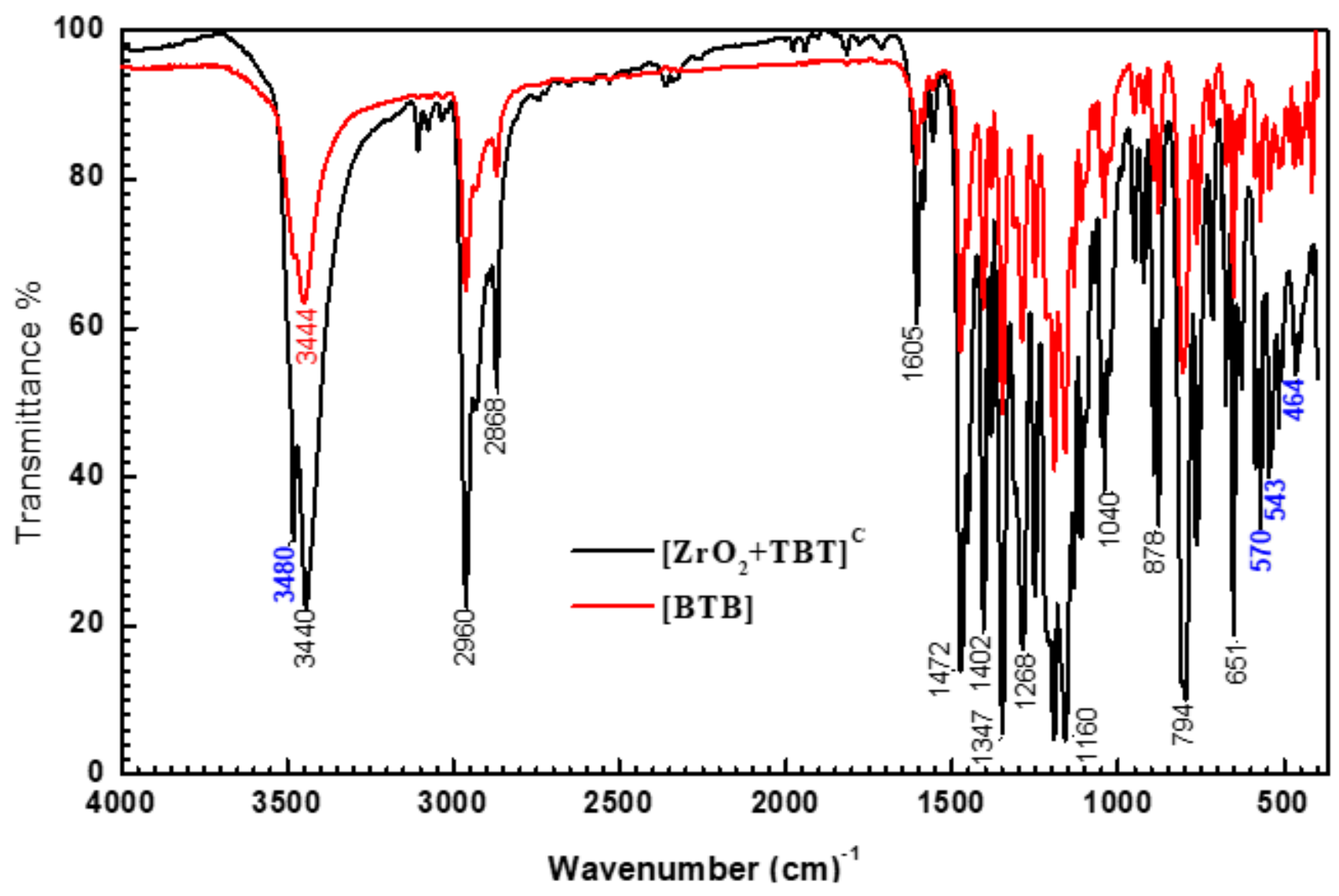

Figure 1

The FTIR spectra experimental data of $[\mathrm{BTB}]$ and $[\mathrm{ZrO} 2+\mathrm{BTB}] \mathrm{C}$. 

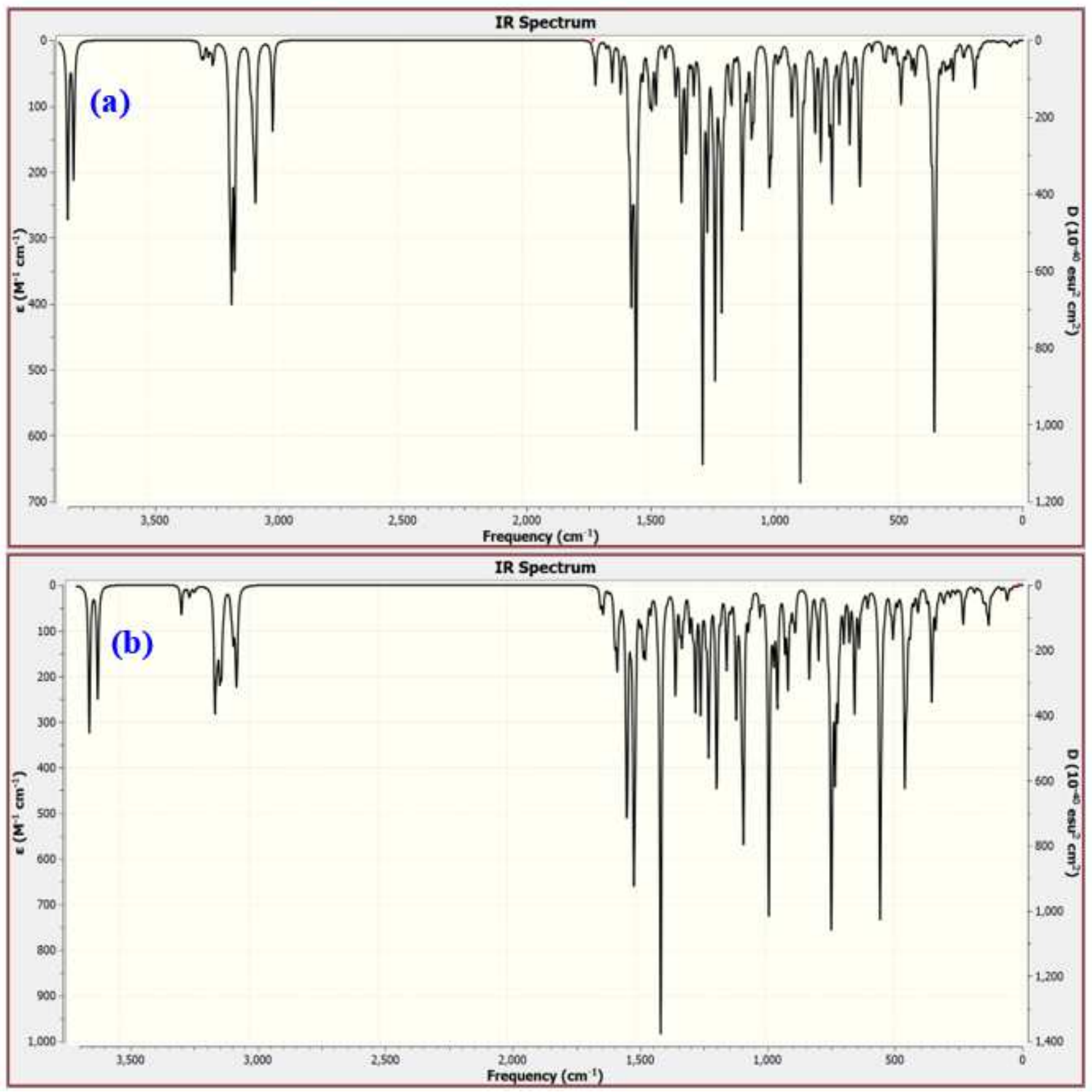

Figure 2

The FTIR spectra Gaussian data of [BTB] and [ZrO2+BTB]C. 


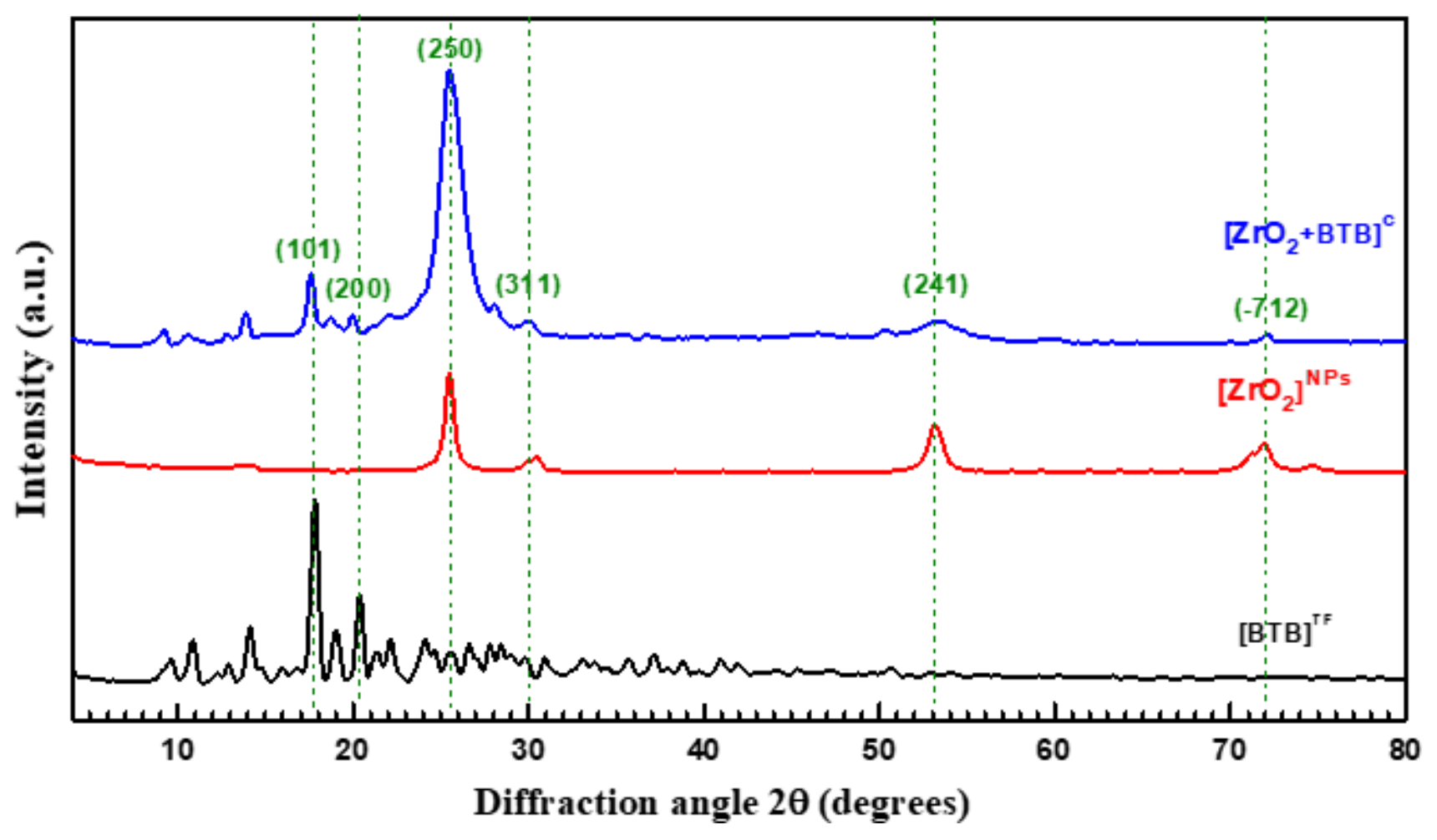

Figure 3

Experimental XRD pattern of [BTB]TF, [ZrO2]NPs and [ZrO2+ BTB]C

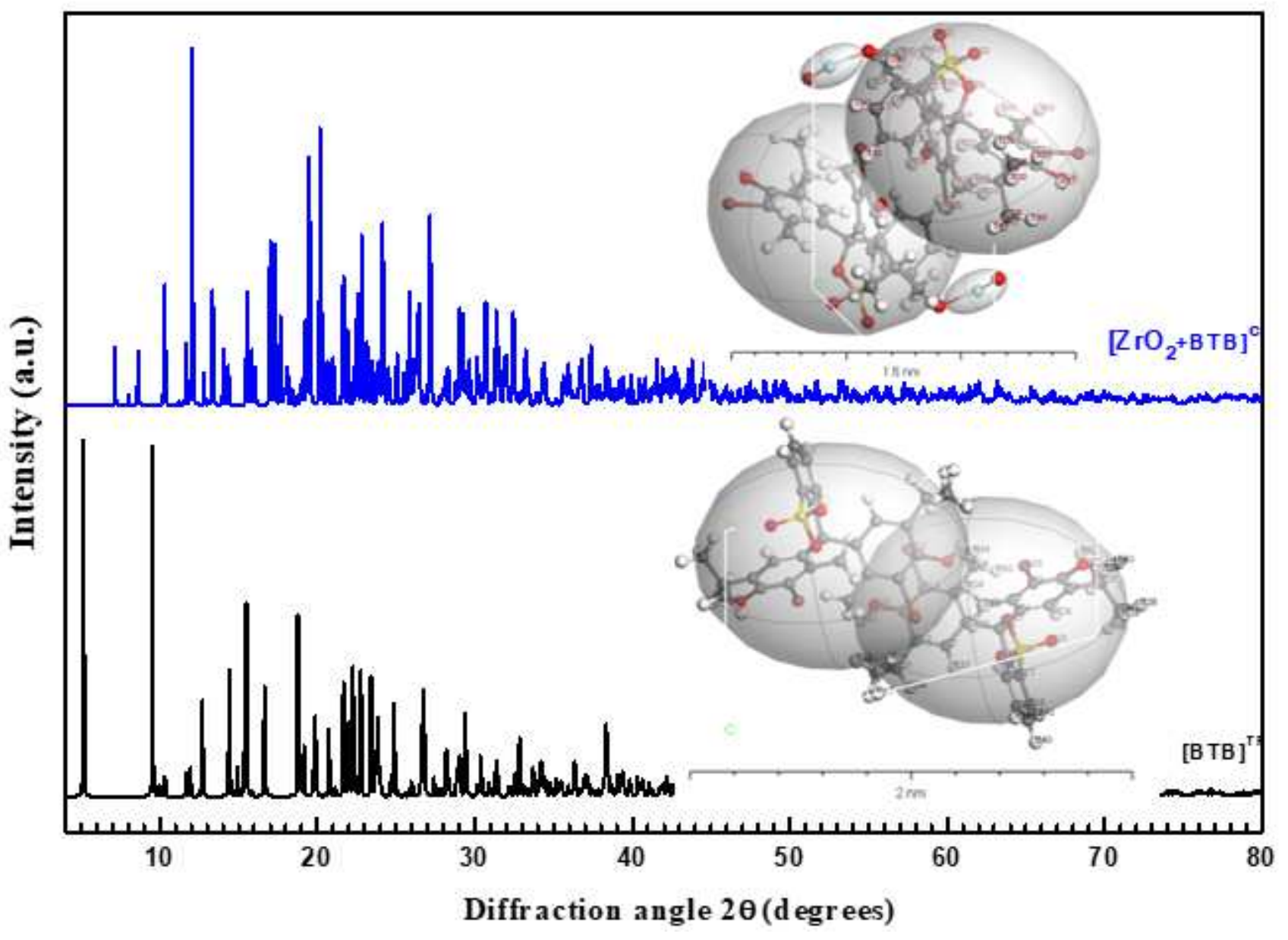


Figure 4

Simulation XRD pattern of [BTB]TF and [ZrO2+ BTB]c by using Material Studio.
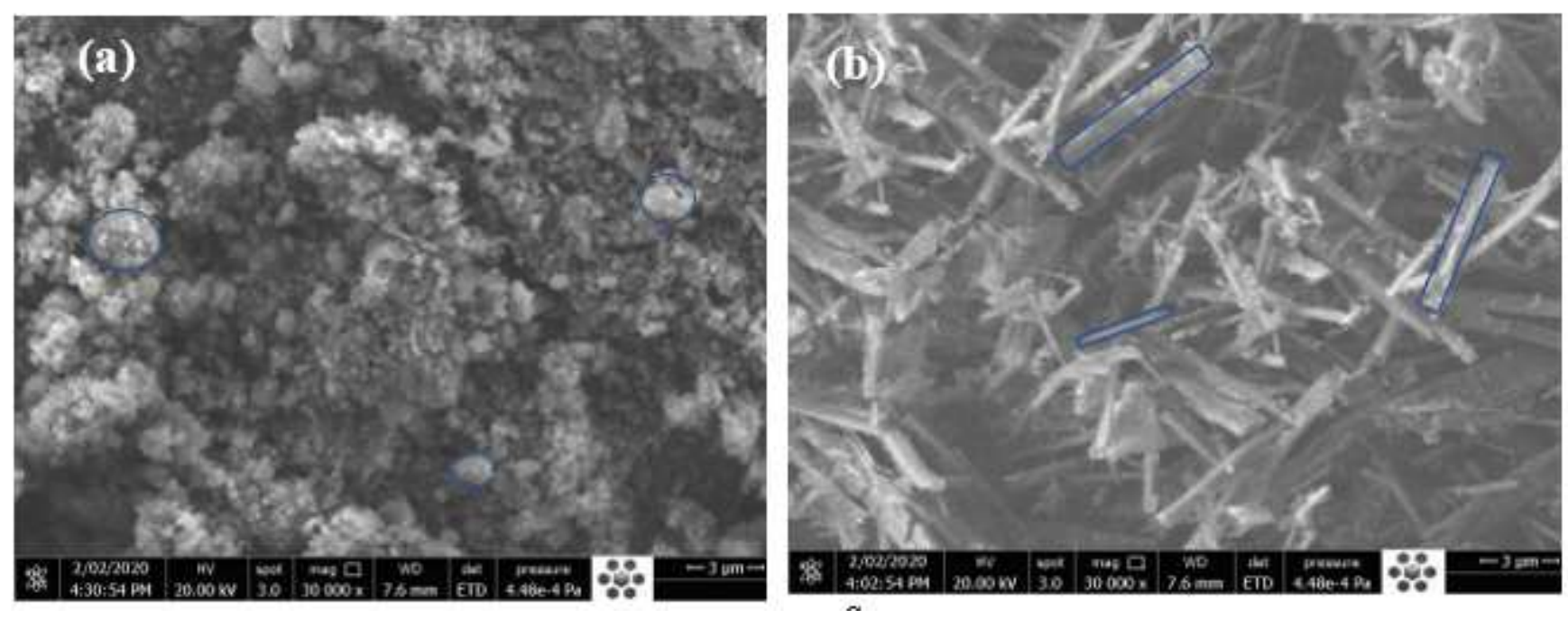

\section{Figure 5}

Top view of the prepared [BTB]TF and [ZrO2+ BTB]C thin films $(150 \mathrm{~nm})$ using the SEM technique. 

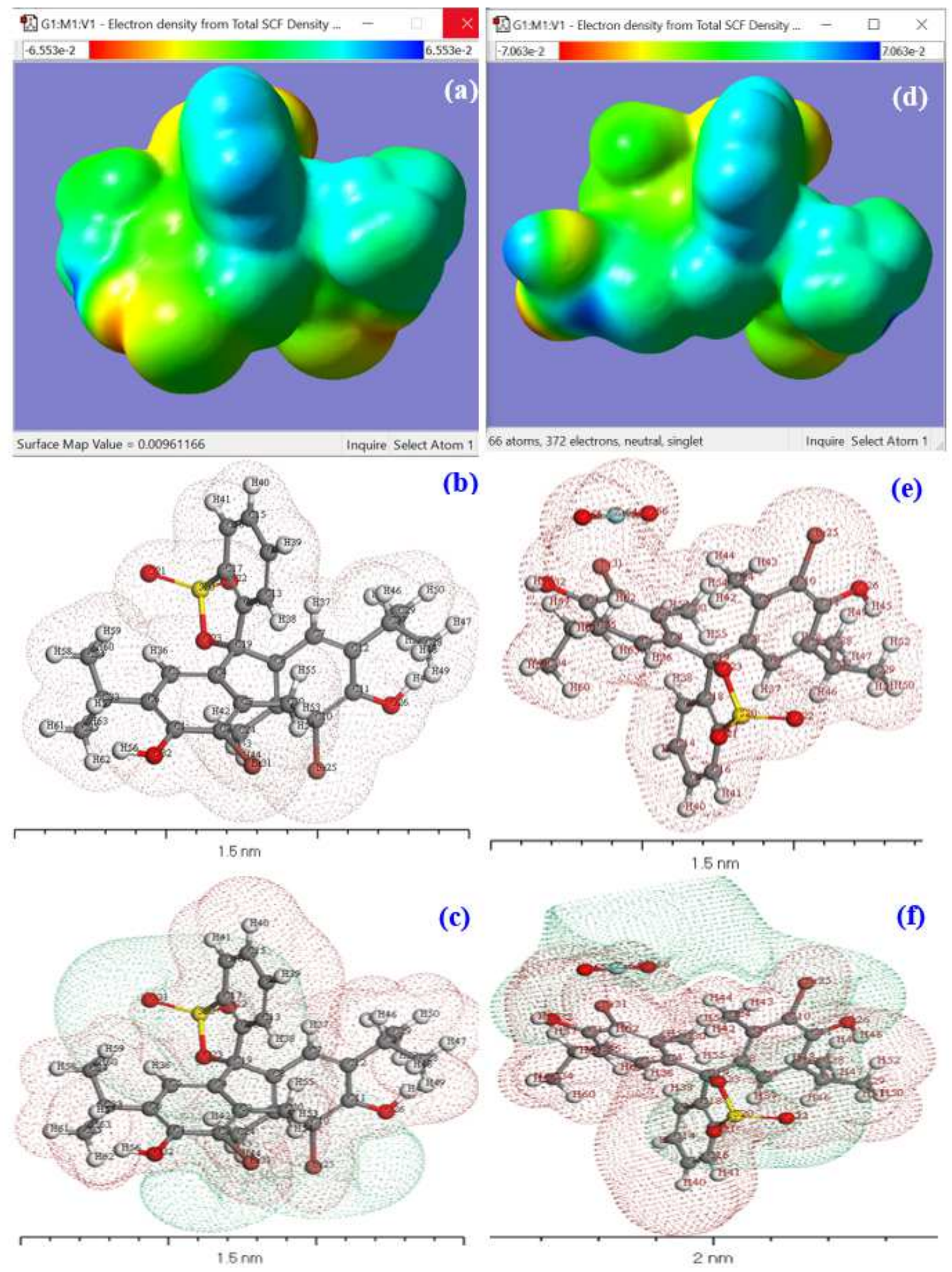

\section{Figure 6}

a) MEP of [BTB]; b) Electron density of [BTB] ; c) Potential of [BTB], d) MEP of [ZrO2+BTB]C; e) Electron density of [ZrO2+BTB]C and e) Potential of [ZrO2+BTB]C by using DFT calculation in material studio and Gaussian software programs 


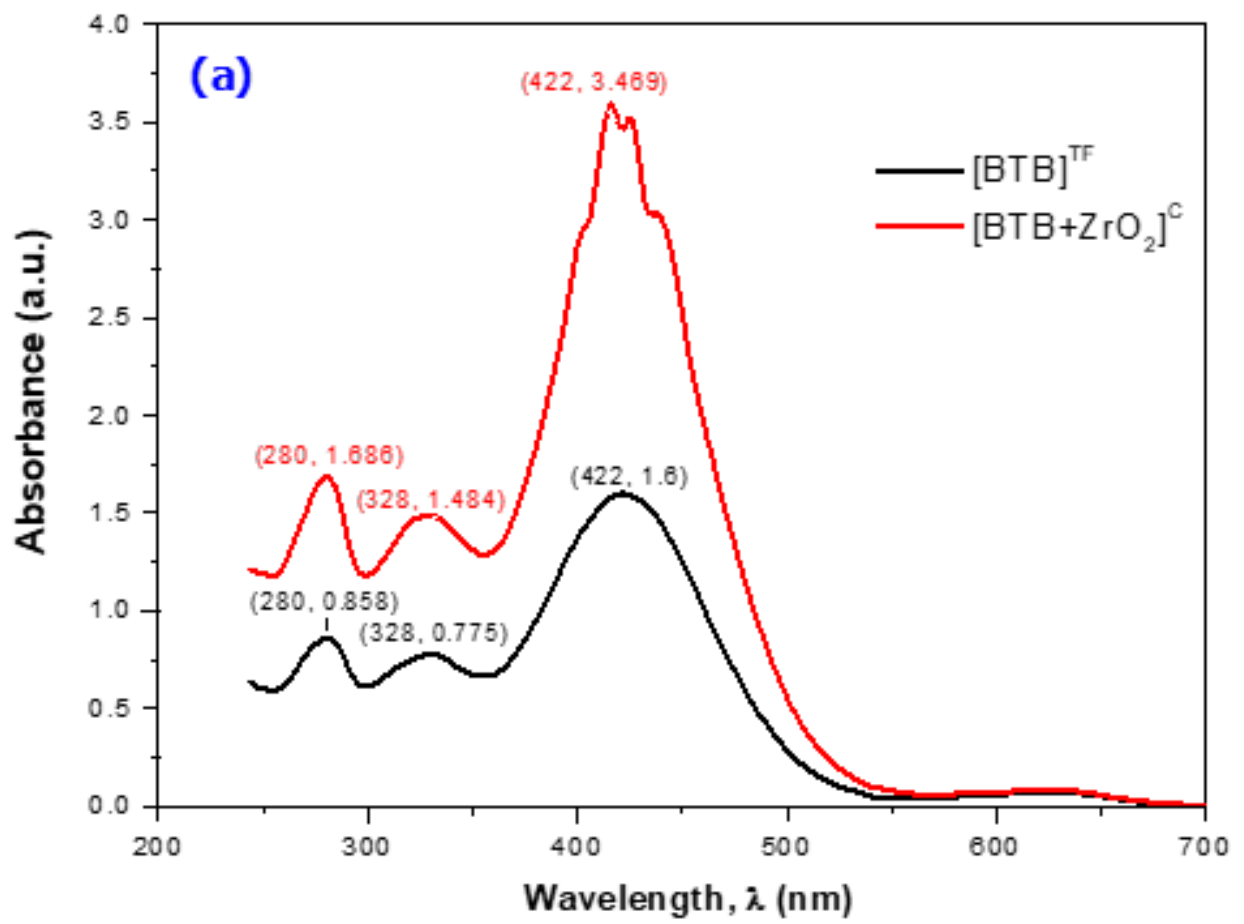

Figure 7

a) UV-vis absorption spectra of [BTB]TF and [ZrO2+BTB]C 


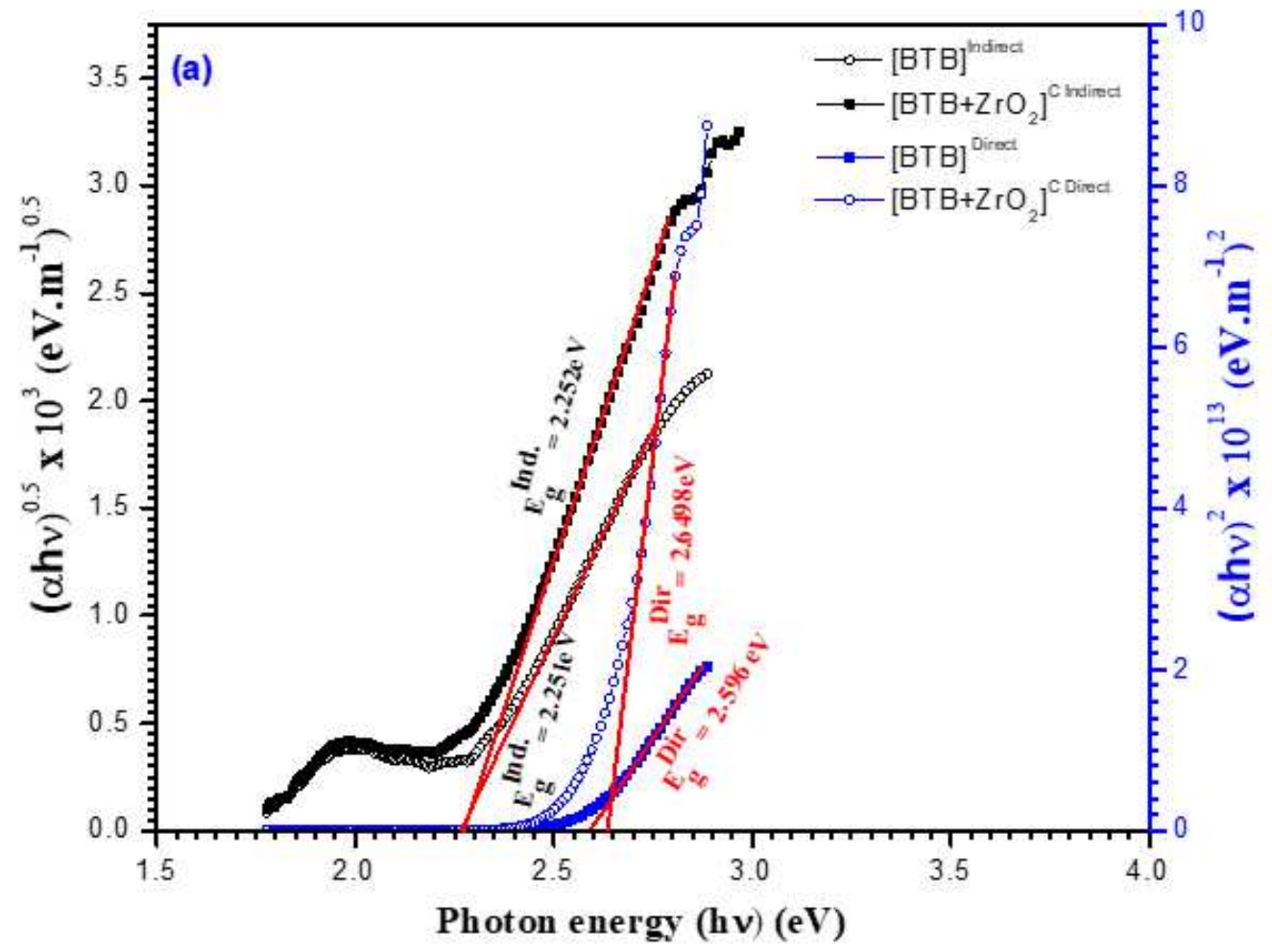

(b)

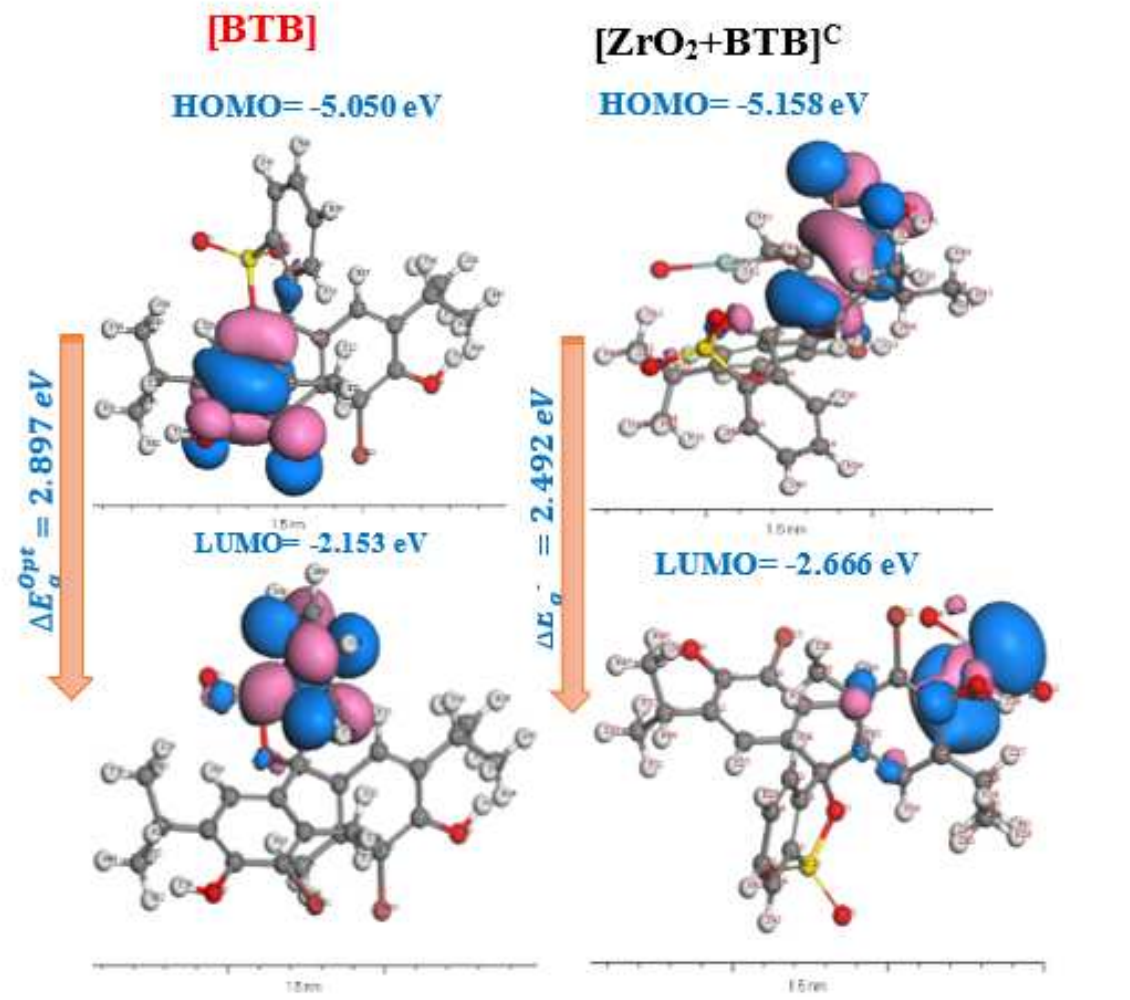

Figure 8

a) The computed band gaps of [BTB]TF and [ZrO2+BTB]C using Tauc's equation. b) Figure is computed HOMO and LUMO using DFT by DMol3. 

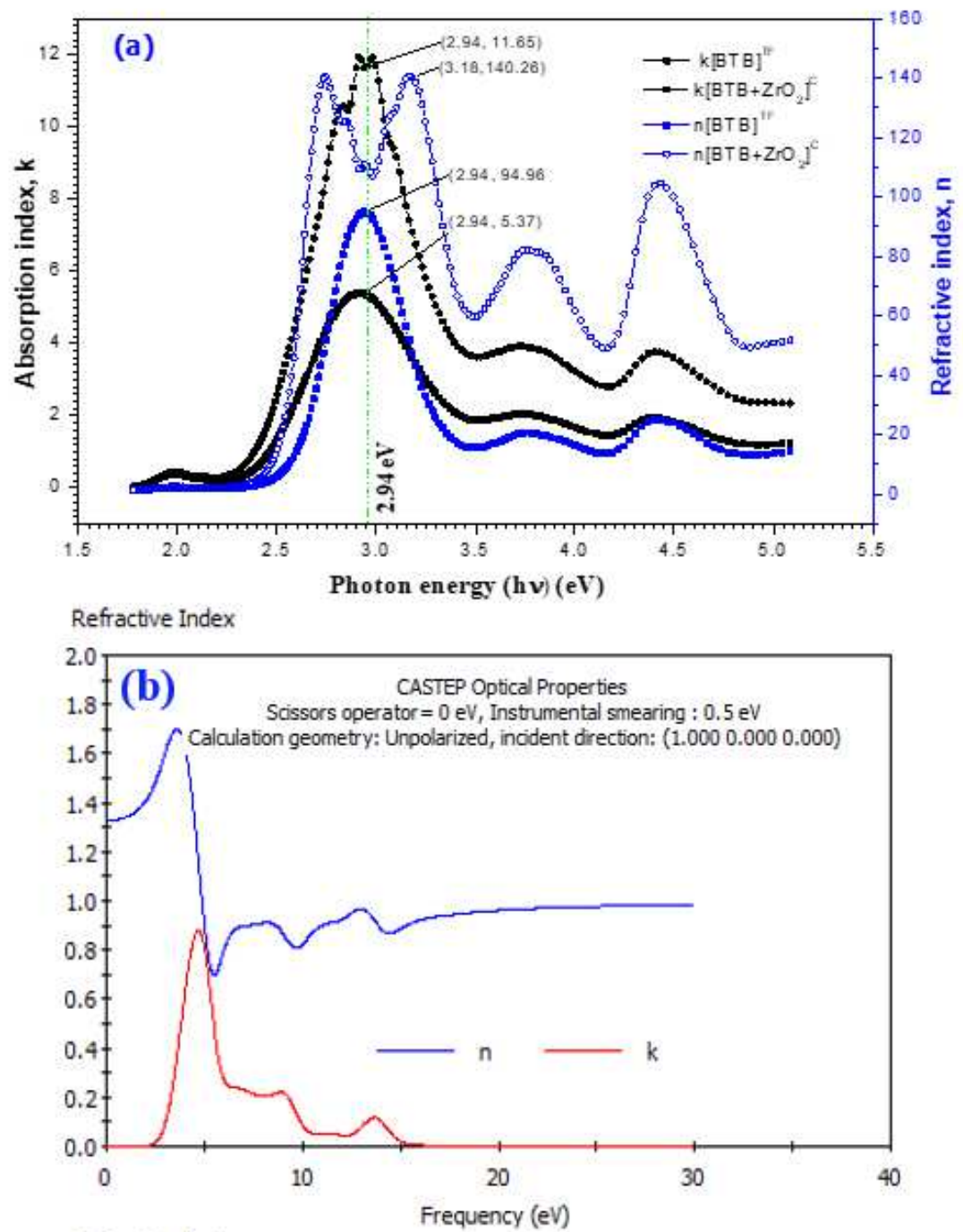

Refractive Index

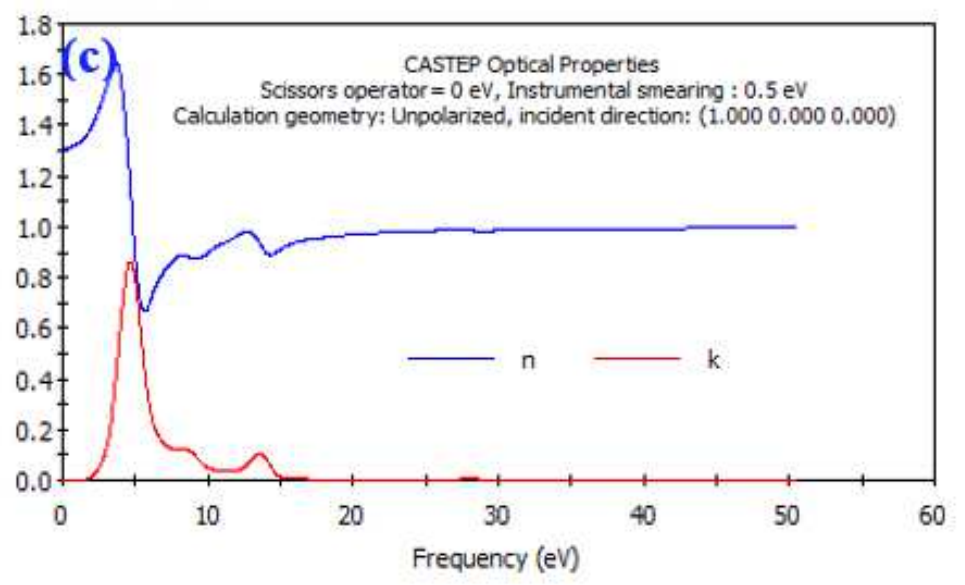

\section{Figure 9}

a) The spectral dependence of both the absorption index $k(\lambda)$ and the refractive index $n(\lambda)$ as a function of hv(eV) for [BTB]TF and [ZrO2+BTB]C. b-c) Simulated [BTB] and [ZrO2+BTB]C using CATSTEP optical properties, respectively. 

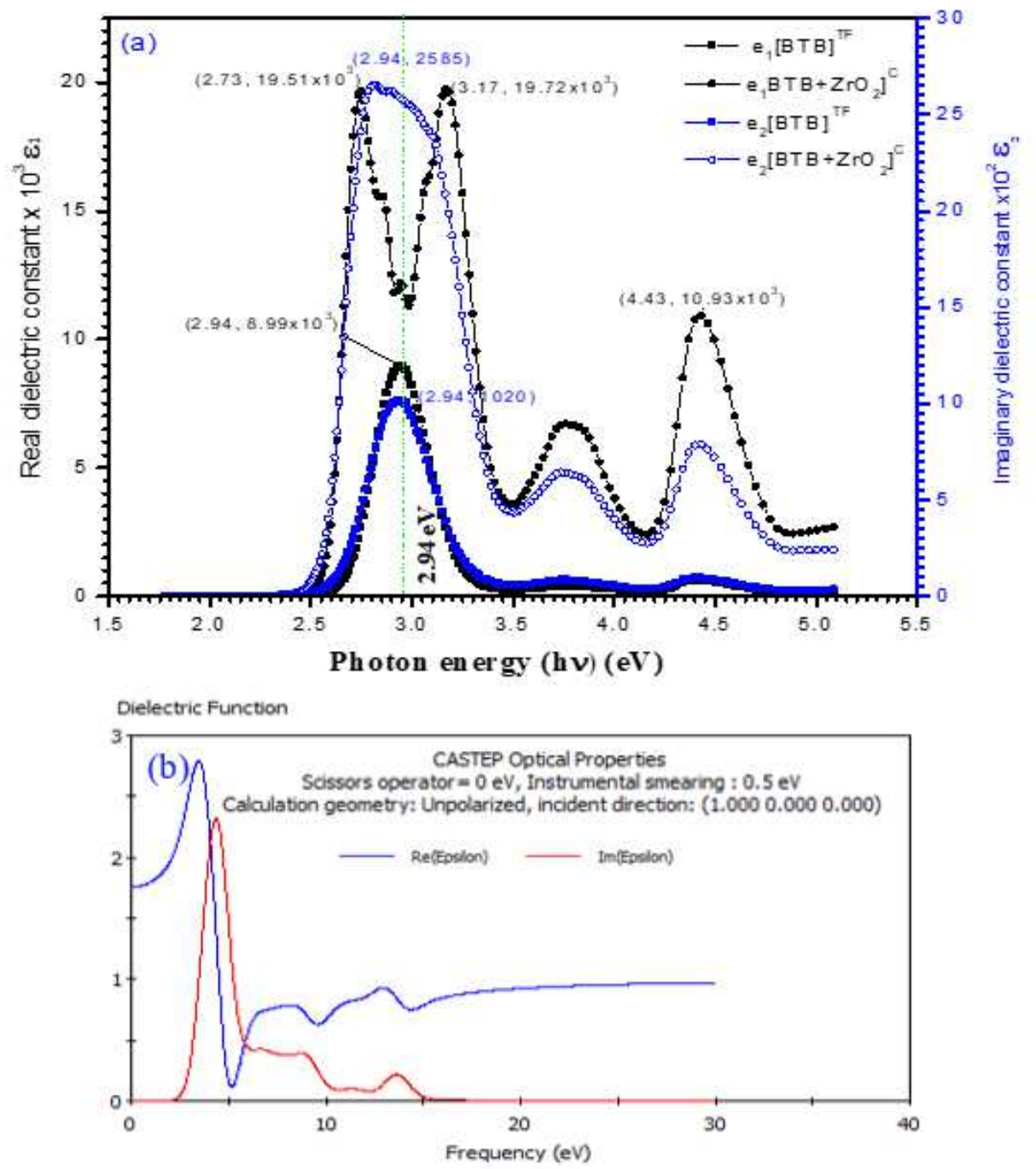

Dielectric Function

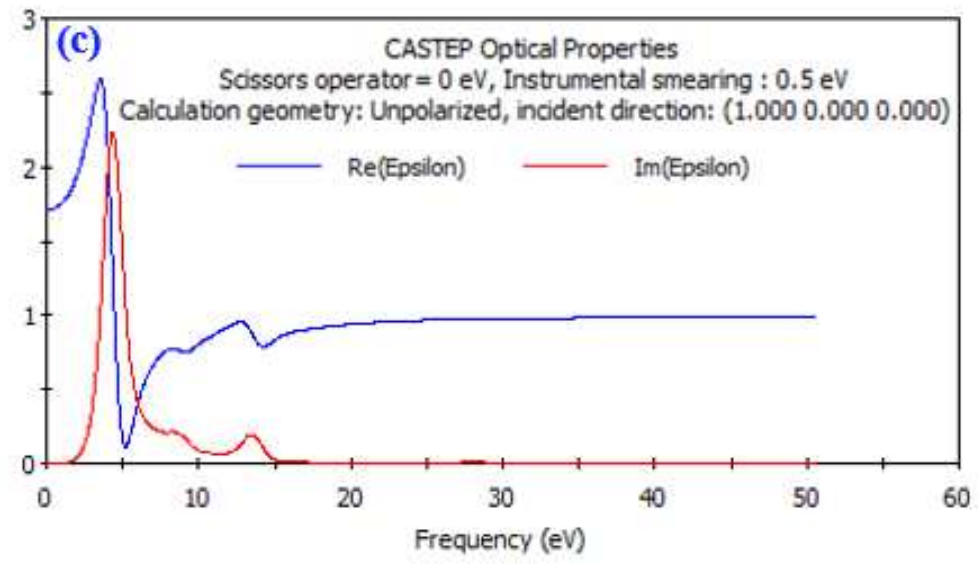

\section{Figure 10}

a) Experimental $\varepsilon_{-} 1(\lambda)$ and $\varepsilon_{-} \_2(\lambda)$ via hv for [BTB]TF and [ZrO2+BTB]C, b) $\otimes 1$ and $₫ 2$ simulation optical prop erties for $[\mathrm{BTB}]$ and $[\mathrm{ZrO} 2+\mathrm{BTB}] \mathrm{C}$ by using CASTEP method in DFT 


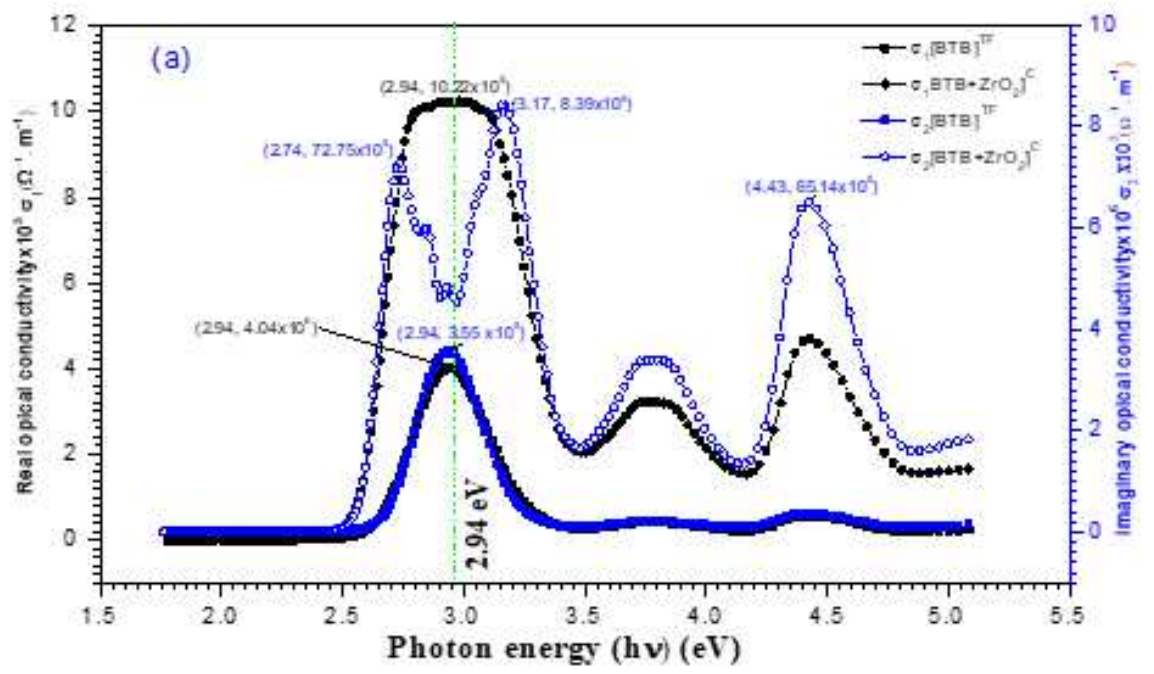

Conductivity (1/fs)

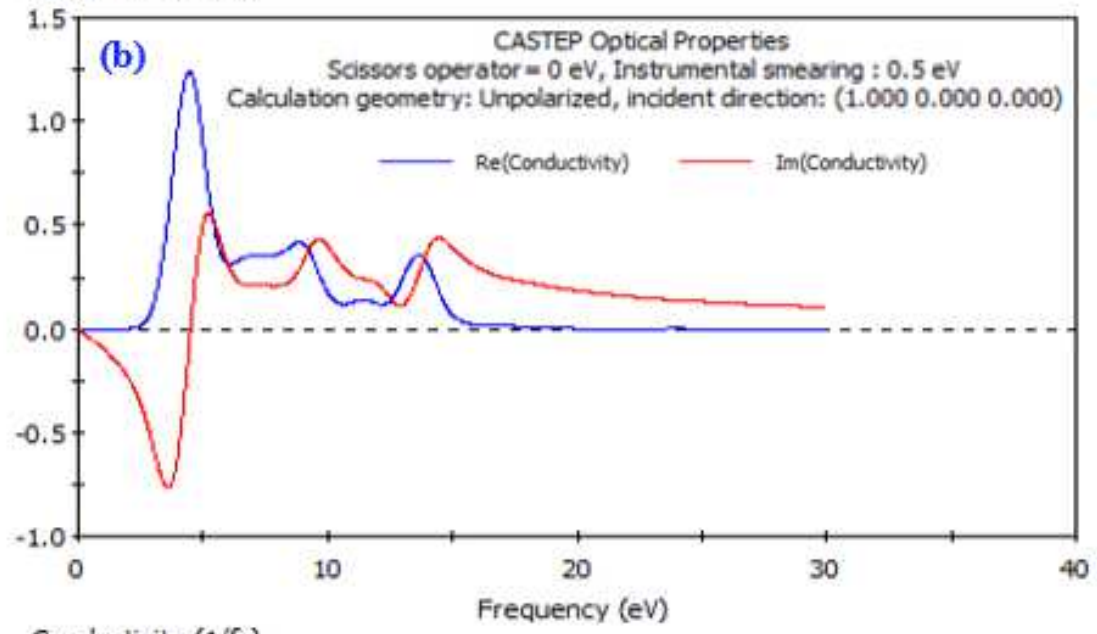

Conductivity (1/fs)

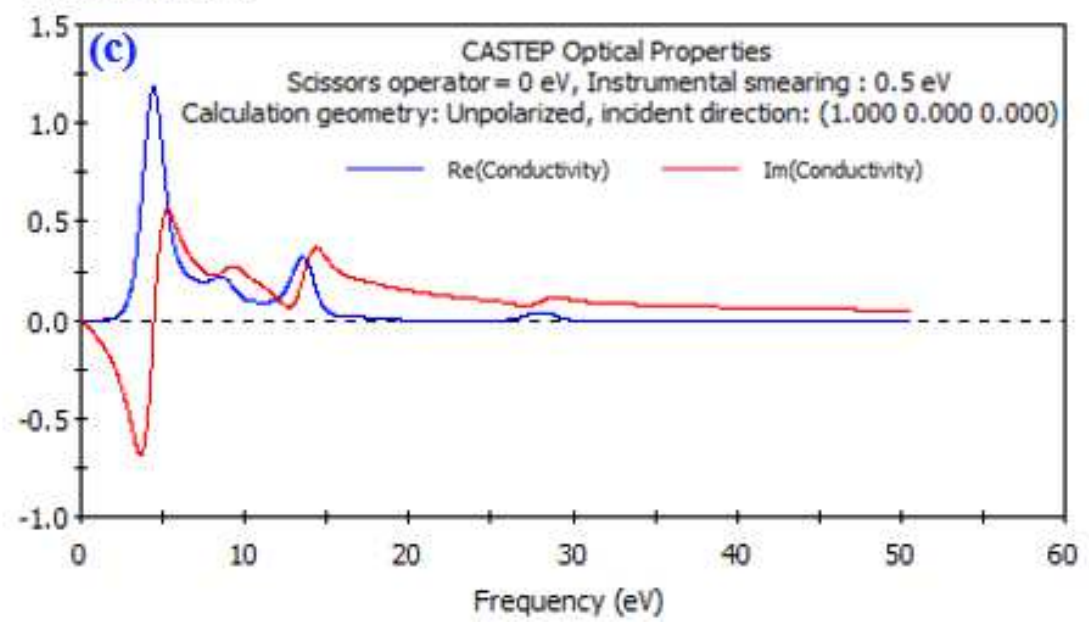

\section{Figure 11}

a) Experimental $\sigma 1$ and $\sigma 2$ via hv for [BTB]TF and [ZrO2+BTB]C, b-c) $\sigma 1$ and $\sigma 2$ simulation optical properties for $[\mathrm{BTB}]$ and [ZrO2+BTB]C by using CASTEP method in DFT, respectively.

\section{Supplementary Files}


This is a list of supplementary files associated with this preprint. Click to download.

- GraphicalAbstract.docx 